\title{
Independencia y neutralidad política de los expertos que integran las autoridades nacionales de reglamentación en Europa
}

\author{
Lourdes de la Torre Martínez' \\ Profesora contratada Doctora de Derecho Administrativo \\ (Acreditada PTU) Universidad de Jaén
}

\begin{abstract}
SUMARIO: I. INTRODUGGIÓN; II. EL FOMENTO DE LAS AUTORIDADES NAGIONALES DE REGLAMENTACIÓN (ANRs) EN LA NORMATIVA EUROPEA DE 2009; III. EL FORTALECIMIENTO DE LA INDEPENDENCIA DE LAS ANRs EN LA NORMATIVA EUROPEA DE 2009; IV. EL CESE DE MIEMBROS DE ANRs ANTES DEL PLAZO ESTABLEGIDO Y FUERA DE LAS GASUSAS LEGALMENTE PREVISTAS ¿SUPONE UNA INJERENCIA EN LA INDEPENDENCIA Y NEUTRALIDAD POLÍTICA DE LA ANR?; 1. En materia de protección de datos; 1.1. Normativa aplicable; 1.2. El caso de Hungría; 1.3. La exigencia de independencia incluye la obligación de respetar la duración del mandato de las autoridades de control hasta su expiración. 2. En materia de telecomunicaciones; 2.1. El caso de España; 2.2. La postura del TS español; 2.3. La interpretación europea del Abogado General: el cese de miembros de una ANR antes de la finalización del mandato menoscaba su independencia; V. REFLEXIONES FINALES.
\end{abstract}

Este trabajo ha sido realizado en el marco del Proyecto subordinado del Plan Nacional I+D+i del Ministerio de Educación y Ciencia titulado: "Las entidades locales, sus relaciones y competencias. Realidad, .efectos y consecuencias de la racionalización y sostenibilidad financiera en Andalucía" (Referencia DER 2016-74843-C3-3-R) del cual soy investigadora principal que se integra en el proyecto coordinador: "Las entidades locales, sus relaciones y competencias. Realidad, efectos y consecuencias de la racionalización y sostenibilidad financiera en clave nacional y europea" (Referencia DER 2016-74843-CR-1-R), cuya investigadora principal es Eloísa Carbonell Parras. Ambos proyectos citados se integran en el Grupo Andaluz de Investigación, Desarrollo e Innovación (PAIDI) SEJ-317 y en el proyecto UJA2014/05/04. 


\section{RESUMEN:}

En este artículo tratamos de dar cuenta de la importancia que adquiere, en el ámbito europeo, sobre todo, la neutralidad e independencia política de los miembros que integran las ANRs. Buena muestra de ello es la normativa europea aprobada en el año 2009, que endurece la independencia de las ANRs, así como el alcance que adquieren -la independencia y la neutralidad política requerida por la normativa europea- ante los supuestos de cese de miembros de organismos reguladores en materia de protección de datos y de telecomunicaciones, antes de expirar el plazo fijado en la norma aplicable y sin mediar causa legal alguna.

\section{PALABRAS GLAVE:}

Independencia, neutralidad política, Autoridades Nacionales de Reglamentación.

\section{ABSTRACT:}

In this article we try to account for the importance that political neutrality and independence of the members integrating the NRAs have specially in Europe. Proof of this are the European regulations approved in 2009, that aim at tightening the independence of the NRAs as well as the scope that acquires - we refer to political neutrality and independence required by European regulations - in the face of the cessation of members of regulatory bodies in the areas of Data Protection and Telecommunications before the end of their mandate and without any legal cause.

KEY WORDS:

Independence, political neutrality, National Regulatory Authorities.

\section{INTRODUCGIÓN.}

En la década de los noventa supone un hito histórico en Europa la liberalización y la apertura de los mercados de redes y servicios, muchos de interés económico general²,

\footnotetext{
Sobre diversas cuestiones relativas al régimen jurídico de los servicios de interés económico general se ha escrito mucho por parte de la doctrina, pueden consultarse, entre otros: ARIÑO ORTIZ, G., Economía y Estado. Crisis y reforma del sector público, Marcial Pons, 1993, Madrid, p. 275 y ss; GARRIDO FALLA, F., "El concepto de servicio público en Derecho español", RAP, n. 135, 1994, p. 7 y ss; JIMÉNEZ-BLANCO CARRILLO DE ALBORNOZ, A., "Servicio público, interés general, monopolio: recientes aportes del Tribunal de Justicia de la Comunidad Europea 1993-1994", REDA, n. 84, octubre-diciembre 1994, p. 592 y 593; GARCÍA DE COCA, J. A., "Régimen jurídico de las empresas encargadas de la gestión de servicios de interés económico general", en VELSACO SAN PEDRO, L. A., Derecho europeo de la competencia, Lex Nova, Valladolid, 2005, p. p. 625 y ss; GARCÍA DE COCA, J. A., "Régimen jurídico de las empresas encargadas de la gestión de servicios de interés económico general", en VELSACO SAN PEDRO, L. A., Derecho europeo de la competencia, Lex Nova, Valladolid, 2005, p. p. 625 y ss; COSCULLUELA
} 
tales como el sector de la energía (gas y electricidad) ${ }^{3}$ y de las comunicaciones electrónicas ${ }^{4}$. Dicha liberalización se ha tratado de implantar de forma progresiva a través

MONTANER, L., LÓPEZ BeníteZ, M., Derecho Público Económico, $1^{\text {a }}$ edición, Iustel, Madrid, 2007, p. 222; LAGUNA DE PAZ, J. C., Servicios de interés económico general, Thomson Reuters, Civitas, Cizur Menor (Navarra), 2009, p. 33; SARMIENTO, D., "La recepción del Derecho de la Unión Europea y en su jurisprudencia de las técnicas de regulación económica”, en MUÑOZ MACHADO, S., ESTEVE PARDO, J. (Dirs.), Derecho de la regulación económica, vol. I (Fundamentos e instituciones de la regulación), Iustel, Madrid, 2009, p. p. 259-262; DÍEZ PICAZO Y PONCE DE LEÓN, L., "Los servicios de interés económico general en el ordenamiento comunitario", MUÑOZ MACHADO, S., (Dir.), Derecho de la regulación económica, vol. I, 2010, p. p. 409-424; SEGURA SERRANO, A., 'Los 'servicios de interés económico general' tras el Tratado de Lisboa: de la excepción a la regulación positiva", Revista de Derecho Comunitario Europeo, Año 15, n. 38, 2011, p. p. 59-96. Varios trabajos de: DE LA TORRE MARTÍNEZ, L., "Derecho Administrativo europeo derivado del Tratado de Lisboa: un nuevo fundamento jurídico en materia de Servicios de Interés Económico General", en Derecho Público de la crisis económica. Transparencia y sector público hacia un nuevo Derecho Administrativo, AEPDA, INAP, Madrid, 2012, p. p. 515-524. "Régimen jurídico y calidad de los servicios de interés general en Europa. El fomento de los llamados 'servicios innovadores' en un mercado digital", en Revista General de Derecho Administrativo, n 43, octubre 2016; "Los servicios de interés general en Europa: hacia la clarificación y determinación jurídica”, en PAREJO ALONSO, L., y VIDA FERNÁNDEZ, J., (Coords), Los retos del Estado y la Administración en el siglo XXI, Libro homenaje al prof. Tomás de la Quadra Salcedo Fernández del Castillo, Tirant lo -Blanch, 2017, pp. 1229-1259.

3 Sobre el sector eléctrico puede consultarse, entre otros: A. JIMÉNEZ-BLANCO CARRILLO DE ALBORNOZ, "La reforma de la Ley del Sector Eléctrico para su adaptación a las exigencias de las directivas comunitarias", en: F. BECKER ZUAZUA/L. M. CAZORLA PRIETO/J. MARTÍNEZ-SIMÁNCAS SÁNCHEZ/J. M. SALA ARQUER (Coords.), Tratado de regulación del sector eléctrico, vol. 1, (aspectos jurídicos), Aranzadi, Cizur Menor, 2009, pp. 241-266; S. MUÑOZ MACHADO/M. SERRANO GONZÁLEZ/M. BACIGALUPO SAGGESE (Dir.), Derecho de la regulación económica, III Sector energético, Tomos I y II, Iustel, Madrid, 2009, PIELOW, J. G., ZIMMERMANN, N., DEL GUAYO CASTIELLA, I., "Precisiones en torno a las Directivas sobre tránsito de electricidad y gas”, Noticias de la Unión Europea, n. 105, 1993, p. p. 37-54; PIELOW, J. C., JANINA LENENDEL, B., "Energy in and for Europe: perspectives of the EU policy \& law after the Lisabon Treaty", en Constitución y democracia: ayer y hoy. Libro homenaje a Antonio Torres del Moral, vol. 3, 2012, p. p. 3051-3068; BACIGALUPO SAGGESE, M, "La Unión Europea y las autoridades reguladoras de la energía”, Revista de derecho de la Unión Europea, n. 16, 2009, p. p. 185-194; también "Los reguladores nacionales de la energía en las nuevas directivas del tercer paquete energético de la Unión Europea: independencia y funciones", Revista de derecho de la competencia y la distribución, n 6, 2010, p. p. 145-152.

4 Como es sabido por todos, el sector de las comunicaciones electrónicas constituye un paradigma en el proceso de liberalización de los servicios de interés económico general en otros sectores (gas, electricidad, energía, transportes). Además, la liberalización de servicios impulsada en el ámbito europeo implica al menos dos cosas: una, la despolitización y el fomento de la neutralidad política en la adopción de las medidas de carácter regulador y en la ejecución de la propia normativa europea; y dos, el principio de separación entre el regulador y los operadores en el ámbito de las comunicaciones electrónicas, del gas y de la electricidad en mayor o menor medida. En el sector de los transportes resaltamos: CARBONELL PORRAS, E., "Transporte urbano y movilidad" en MUÑOZ MACHADO, S., (Dir.), Tratado de Derecho Municipal, $3^{\circ}$ edición, iustel, 2011, Madrid; CARBONELL PORRAS, E., "Infraestructuras del transporte y sector público estatal”, en la obra colectiva MENÉNDEZ MENENDEZ, P., (Dir.), Régimen Furídico del Transporte Terrestre: Carreteras y ferrocarril, Tomo I, Thomson Reuters Aranzadi, Cizur Menor (Navarra) 2014, p. p. 889- 998; CARBONELL PORRAS, E., "La movilidad sostenible urbana, un planteamiento integral del desplazamiento de personas y cosas en las ciudades", en BOIX PALOL, A., y MARZAL RAGA, R., Ciudad y movilidad. La regulación de la movilidad urbana sostenible, Universidad de Valencia, 2014, p. p. 91-106; 
de Reglamentos y, sobre todo, de Directivas sectoriales, si bien este proceso aún no ha sido concluido de forma óptima. A lo anterior se suman las ideas de la neutralidad, independencia o incluso desideologización que surgen en el ámbito del sector bancario con la creación del Sistema de Bancos Centrales Europeos (SBCE), establecido en el Tratado de la Unión Europea, en la versión de Maastricht aprobada en 1992.

Con este fin, en 1997 se aprueba un primer paquete normativo, reformado de forma global en 2002 y, por último, se vuelve a modificar en $2009^{5}$. Con carácter general, tanto en el ámbito de las comunicaciones electrónicas ${ }^{6}$ como en el de la energía, la legislación europea de 2009 introduce una novedad importante, y es que trata de garantizar la independencia de las ANRs y de fortalecer sus poderes reguladores. A lo anterior se suma la creación de unos organismos de cooperación dentro de la estructura de las instituciones comunitarias: el Organismo de Reguladores Europeos de Comunicaciones Electrónicas (en lo sucesivo ORECE), o también conocido en inglés por BEREC, Body of European Regulators for Electronic Communications, y la

CANO CAMPOS, T., "El transporte urbano por carretera”, MENÉNDEZ GARCíA, P., (Coord.), Régimen jurídico del transporte terrestre: carreteras y ferrocarril, vol. 1, 2014 (Régimen jurídico del transporte terrestre. Tomo I. / BERMEJO VERA, J. (Coord.), p. p. 751-832; RUIZ OJEDA, A., (Dir.), VI. Transportes, Colección Derecho de la Regulación, Iustel, 2010.

5 En este escenario resaltamos el Informe de la Comisión europea de 1 de junio de 2010. En él se pone de manifiesto que los ciudadanos y las empresas disfrutan de un mayor surtido de servicios y de precios más económicos debido a que existe más competencia; sin embargo, el Informe denuncia que un mercado único de las telecomunicaciones en la Unión Europea sigue estando lejos de ser una realidad. Ello es debido a diversas causas, entre las que resalta que los reguladores nacionales de las telecomunicaciones aplican soluciones diferentes a asuntos similares en la ejecución de la normativa comunitaria. Informe sobre una nueva Agenda Digital para Europa: 2015.eu (2009/2225(INI)) de la Comisión de Industria, Investigación y Energía del Parlamento Europeo. Esta opinión crítica de la Comisión no es nueva, aparece ya por vez primera en la Comunicación sobre la revisión del marco regulatorio de las comunicaciones electrónicas de 29 de junio de 2006, se reitera en los informes periódicos de 2007 y 2008, y ahora constituye una idea crucial en las Directivas de 2009 y en el Reglamento de 2009 que integran el tercer paquete "telecom". Todo lo anterior ha motivado la renovación, en el año 2009, del marco regulador europeo en materia de comunicaciones electrónicas, y viene a conformar el denominado tercer paquete "telecom". En particular se integra por: la Directiva 2009/136/CE del Parlamento Europeo y del Consejo, de 25 de noviembre de 2009, por la que se modifica la Directiva 2002/22/CE relativa al servicio universal, la Directiva 2002/58/CE relativa al tratamiento de los datos personales y el Reglamento $(\mathrm{CE}) \mathrm{n}^{\circ}$ 2006/2004 sobre la cooperación en materia de protección de los consumidores; la Directiva 2009/140/CE del Parlamento Europeo y del Consejo, de 25 de noviembre de 2009, por el que se modifican la Directiva 2002/21/CE relativa a un marco regulador común de las redes y servicios de comunicaciones electrónicas, la Directiva 2002/19/CE relativa al acceso y la Directiva 2002/20/CE relativa a la autorización, y el Reglamento (CE) n 211/2009 del Parlamento Europeo y del Consejo, de 25 de noviembre de 2009, por el que se establece el Organismo de Reguladores Europeos de las Comunicaciones Electrónicas (ORECE) y la Oficina.

6 ANGULO, N., ANGULO, A., FERNANDEZ, D. "Neutralidad en la red y competencia en la UE: la regulación del mercado de las comunicaciones electrónicas tras el Reglamento sobre el mercado único de las telecomunicaciones", Revista de derecho de la competencia y la distribución, 2015, número 17. 
Agencia de Cooperación de los Reguladores de la Energía (ACER) creada mediante el Reglamento 713/2009, de 13 julio de 20097.

Este trabajo tiene por objeto estudiar cómo la liberalización de servicios y redes en determinados sectores - impuesta por la normativa europea - y la consecución de un mercado único, llevan aparejadas la promoción de la neutralidad política y la independencia en la formación de las Autoridades Nacionales de Reglamentación, -las llamadas ANRs -, frente a los agentes del mercado y a los gobiernos nacionales ${ }^{8}$. También, tratamos de dar cuenta de un problema jurídico que se está planteando en los últimos tiempos: hasta qué punto el cese de los miembros de las ANRs, antes de plazo fijado y por los motivos no previstos como causa de cese legalmente, supone una injerencia de la citada independencia y neutralidad política de tales Autoridades.

Desde la perspectiva del Derecho interno español, si atendemos a la Constitución española de 1978, es preciso recordar que el ejercicio de la neutralidad política y la adopción de criterios técnicos en las decisiones de los poderes públicos se ha de

JIMÉNEZ-BLANCO CARRILLO DE ALBORNOZ, A, "La reforma de la Ley del Sector Eléctrico para su adaptación a las exigencias de las directivas comunitarias", Tratado de regulación del sector eléctrico, vol. 1, 2009 (Aspectos jurídicos), p. p. 241-266

8 Sobre regulación económica se ha escrito mucho por parte de la doctrina, entre otros: DE LA CRUZ FERRER, J., Principios de regulación económica en la Unión Europea, Madrid, Instituto de Estudios Económicos, 2002; DE LA CUÉTARA MARTÍNEZ, J. M., "El 'diálogo regulatorio' como base para la confianza en la regulación", en REDETI, Revista de Derecho de las Telecomunicaciones e Infraestructuras en red, n. 9, 2006, p. p. 11-38; MONTERO PASCUAL, J. J., "Regulación, desregulación y la última crisis del servicio público", en REDETI, Revista de Derecho de las Telecomunicaciones e Infraestructuras en red, n. 30, 2007; MUÑOZ MACHADO, S., "Fundamentos e instrumentos jurídicos de la regulación económica", en Derecho de la Regulación Económica. i. Fundamentos e instituciones de la regulación, Madrid, Iustel, 2009; ESTEVE PARDO, J., "El encuadre de la regulación de la economía en el Derecho público", en Derecho de la Regulación Económica. i. Fundamentos e instituciones de la regulación, Madrid, Iustel, 2009; ESTEVE PARDO, J., "La regulación de industrias y public utilities en los Estados Unidos de América. Modelos y experiencias", en Derecho de la Regulación Económica. I. Fundamentos e instituciones de la regulación, Madrid, Iustel, 2009; ESTEVE PARDO, J., "La revisión judicial de las decisiones de las autoridades reguladoras. Jurisprudencia del Tribunal Supremo y la Audiencia Nacional", Derecho de la Regulación Económica. i. Fundamentos e instituciones de la regulación, Madrid, Iustel, 2009; ARIÑO ORTIZ, G., "El control judicial de las entidades reguladoras: la necesaria expansión del Estado de Derecho", Revista de Administración Pública, nº 182, 2010; BETANCOR RODRÍGUEZ, A., Regulación: mito y derecho, Madrid, Civitas, 2010; MONTERO PASCUAL, J. J., "Régimen jurídico de los servicios de interés general", Financiación de obligaciones de servicio público, Valencia, Tirant lo Blanch, 2010; SANTAMARÍA PASTOR, J. A., "Sectores regulados y competencia: un dilema complejo", Las técnicas de regulación para la competencia: una visión horizontal de los sectores regulados, Madrid, Iustel, 2011; ESTEVE PARDO, J., "Origen, principios y técnicas de la regulación de sectores económicos de interés general", en La regulación económica. En especial, la regulación bancaria. Actas del IX Congreso Hispano-Luso de Derecho Administrativo, Madrid, Iustel, 2012; MONTERO PASCUAL, J. J., La Comisión Nacional de los Mercados y de la Competencia. Entre la actividad administrativa de regulación y el Derecho de la competencia, Valencia, Tirant lo Blanch, 2013; MONTERO PASCUAL, J. J., "La actividad administrativa de regulación: definición y régimen jurídico", Revista digital de Derecho Administrativo, n. 12, segundo semestre/2014, p. p. 23-44. 
realizar con respeto al principio de objetividad y de servicio a los intereses generales, con pleno sometimiento a la ley y al Derecho (art. 103.1 Constitución española). También resulta indiscutible que el fomento de la neutralidad política en el ejercicio de potestades administrativas no escapa al control judicial (art. 106.1 Constitución española), aunque éste tenga sus peculiaridades y sus límites, propios de un control de la discrecionalidad técnica. Dicho control tiene una larga tradición en materia de función pública cuando los jueces pretenden controlar las decisiones de los órganos administrativos para la selección de personal al servicio de las Administraciones públicas o en materia de nombramientos de Magistrados y jueces ${ }^{9}$. De este modo, el reconocimiento de un espacio neutral es compatible con un control jurisdiccional y una supervisión parlamentaria por los órganos competentes de cada Estado miembro ${ }^{10}$.

En definitiva, se trata de lograr un equilibrio entre dos polos: de un lado, la armonización a nivel europeo, y de otro lado, el respeto a la autonomía institucional de cada Estado miembro para que adopte las medidas europeas de acuerdo a su ordenamiento jurídico interno. Por ello, en este ámbito cobra una especial importancia la independencia de las ANRs frente a las eventuales influencias políticas y de los operadores de los citados sectores ${ }^{11}$, lo que permite a los miembros de las ANRs ejercer sus funciones como expertos de reconocido prestigio y adoptar sus decisiones de forma independiente y neutral ${ }^{12}$.

En particular, este estudio adquiere especial interés a raíz de que el Tribunal de Justicia de la Unión Europea (en adelante TJUE) se pronuncia en la sentencia de

9 FERNÁNDEZ, T. R., "La discrecionalidad técnica: un viejo fantasma que se desvanece", RAP, n. 196, enero-abril 2015, p. p. 211-227. MUÑOZ MACHADO, S., y ESTEVE PARDO, J., Regulación Económica I. Fundamentos e Instituciones de la Regulación, Iustel, 2009; MONTERO PASCUAL, J. J., "La actividad administrativa de regulación", Revista Digital de Derecho Administrativo, n. 12, segundo semestre/2014, p. p. 23-44.

10 Según MARTI DEL MORAL, A., tales afirmaciones suponen una transformación indirecta en las relaciones entre los entes públicos y el Gobierno de la nación, por cuanto parece que se altera la potestad de dirección de la Administración pública y la potestad ejecutiva (art. 97.1 CE), así como el principio de jerarquía y otros que garantiza el art. 103.1 de la Constitución española respecto a la organización y funcionamiento de la Administración pública. Ahora bien los cambios que puedan afectar al derecho nacional interno se aceptan por la cláusula de supranacionalidad del art. 93.1 CE que permitió incorporar el derecho comunitario, originario y derivado, con sus caracteres de primacía sobre el derecho interno y de efecto directo en nuestro país. MARTI DEL MORAL, A., "La incidencia del Derecho comunitario en la formación de las autoridades reguladoras como administraciones independientes", en REBOLLO PUIG, M., CARBONELL PORRAS, E., y LÓPEZ BENÍTEZ, M., (Coords.), Régimen jurídico básico de las Administraciones Públicas. Libro Homenaje al Profesor Luis Cosculluela, Iustel, 2015.

11 BETANCOR RODRÍGUEZ, A, "Autoridad de la competencia y reguladores sectoriales en el contexto del mercado con posición de dominio: Ideas y reflexiones a partir de la Sentencia del Tribunal General (Sala Octava) de 29 de marzo de 2012 (asunto T-398/07, España/Comisión)", Revista de derecho de la competencia y la distribución, n. 11, 2012, p. p. 17-34.

12 Sobre el origen y la evolución de las Administraciones independientes en el Derecho español: NAVARRO RODRÍGUEZ, P., "La reforma de los organismos reguladores en España", Actualidad Adminis- 
8 de abril de 2014 (asunto C-288/2012, Comisión vs. Hungría), sobre el cese de una autoridad de control en materia de protección de datos, el "Supervisor" de protección de datos, antes de que expire el periodo de vigencia de su mandato previsto en la legislación de Hungría, tras el nombramiento de una figura nueva, la "Autoridad" del citado organismo regulador ${ }^{13}$. Mayor interés aún suscita si tenemos en cuenta que, con posterioridad, en España, el TS mediante Auto de 3 de julio de $2015^{14}$ ha planteado varias cuestiones prejudiciales al TJUE ${ }^{15}$, partiendo y conociendo el prece-

trativa, n. 12, junio de 2012, pp. 1486-1498. NAVARRO RODRÍGUEZ, P., "La nueva Comisión Nacional de los Mercados y la Competencia: naturaleza, régimen jurídico e independencia", Revista General del Derecho Administrativo, Iustel, n. 34, 2013; GÓMEZ ALESSANDRI, J., "La Comisión Nacional de los Mercados y la Competencia: planteamientos iniciales y resultado", Diario La Ley, n. 8168, 2013; TORAL OROPESA, P. "La Comisión Nacional de los Mercados y la Competencia", Actualidad furídica Aranzadi, n. 869, 2013, p.10 y ss; GÓRRIZ LÓPEZ, C., "La Comisión Nacional de los Mercados y la Competencia”, Revista de Derecho Mercantil, n. 291, 2014, p.359-400; BROKELMANN, H., VALLINA, R., "La nueva Comisión Nacional de los Mercados y la Competencia", Comunicaciones en propiedad industrial y derecho de la competencia, n. 71, 2014, p. 7-26; SALA ARQUER, J.M., "El Estado neutral: contribución al estudio de la Administraciones independientes", REDA n. 42, 1984, p. p.. 401-422; LÓPEZ RAMÓN, F., "El Consejo de Seguridad Nuclear: un ejemplo de Administración independiente", RAP, n. 124, 1991, p. 189 y ss, también publicado en Administración instrumental. Homenaje a M. Clavero Arévalo, Civitas, tomo I, 1994, págs. 575-597; POMED SÁNCHEZ, L.A., "Fundamento y naturaleza jurídica de las Administraciones independientes", RAP, n. 132, 1993, p.p. 117 y ss; GARCÍA LLOVET, E., "Autoridades administrativas independientes y Estado de Derecho", RAP, núm. 131, 1993, p. p. 61 y ss; BETANCOR RODRÍGUEZ, A., Las Administraciones independientes. Un reto para el Estado social y democrático de Derecho, Tecnos, 1994; FERNÁNDEZ RODRÍGUEZ, T.R., "Reflexiones sobre las llamadas Administraciones independientes", La Administración instrumental. Homenaje a M. Clavero Arévalo, Civitas, tomo I, 1994, págs. 427 y ss; COSCULLUELA MONTANER, L., LÓPEZ BENÍTEZ, M., Derecho público económico, 2012, p. 131-136; MARTI DEL MORAL, A., "La incidencia del Derecho comunitario en la formación de las autoridades reguladoras como administraciones independientes", en REBOLLO PUIG, M., CARBONELL PORRAS, E., y LÓPEZ BENÍTEZ, M., (Coords.), Régimen jurídico básico de las Administraciones Públicas. Libro Homenaje al Profesor Luis Cosculluela, Iustel, 2015.

13 PAZOS CASTRO, R., "La problemática de cómo garantizar la independencia de las Agencias Nacionales de Protección de Datos: el caso húngaro. Comentario a la STJUE de 8 de abril de 2014 (asunto G-288/12, Comisión /Hungría)", Boletín CeDe UsC, Sección Comentarios Xurisprudencia 2014.

14 Recurso número 506/2013, de 3 de julio de 2015.

15 El TS acuerda plantear tres cuestiones prejudiciales: "A) La interpretación de la Directiva 2002/21/ CE, del Parlamento Europeo y del Consejo, de 7 de marzo de 2002, relativa a un marco regulador común de las redes y los servicios de comunicaciones electrónicas, ipermite considerar compatible con ella, desde la perspectiva de salvaguarda efectiva de los intereses generales que competen al órgano nacional de regulación en esta materia, la creación por el legislador nacional de un órgano de regulación y supervisión que responda a un modelo institucional de carácter no especializado, que fusiona en un solo organismo los órganos de control en el ámbito de la energía, las telecomunicaciones y la competencia, entre otros, existentes hasta entonces?; B) ¿Las condiciones de "independencia" de las autoridades nacionales de regulación en materia de redes y servicios de comunicaciones electrónicas, a las que se refiere el artículo 3, apartados 2 y 3 bis de la Directiva 2002/21/CE, modificada por la Directiva 2009/140/CE, han de ser análogas a las requeridas para las autoridades nacionales de control de protección de datos personales según el artículo 28 de la Directiva 95/46/CE?; C) ¿Sería aplicable la doctrina contenida en la sentencia del Tribunal de Justicia de la Unión Europea de 8 de abril de 2014 al supuesto en que los responsables de una autoridad nacional de reglamentación de las telecomunicaciones son 
dente húngaro citado, tras los ceses del, por entonces, Presidente y uno de los Consejeros de la hoy extinta Comisión del Mercado de las Telecomunicaciones (en adelante CMT ${ }^{16}$. En la actualidad ya se han dictado las sentencias correspondientes por el TJUE, de 19 de octubre de 2016 (asunto C 424/15) y por el TS, de 3 de noviembre de 3016 (recurso no $\left.^{0} 77 / 2016\right)^{17}$.

En este contexto cobran especial consideración, la Ley 2/2011 de 4 de marzo de Economía Sostenible ${ }^{18}$, que recogía una regulación importante relativa a las ANRs, y la Ley 3/2013, de 4 de junio, de creación de la Comisión Nacional de los Mercados y la Competencia (en lo sucesivo CNMG) ${ }^{19}$, que agrupa las funciones relativas al correcto funcionamiento de los mercados y sectores supervisados por la Comisión Nacional de la Energía, la Comisión del Mercado de las Telecomunicaciones, la Comisión Nacional de la Competencia, el Comité de Regulación Ferroviaria, la Comisión Nacional del Sector Postal, la Comisión de Regulación Económica Aeroportuaria y el Consejo Estatal de Medios Audiovisual. Por último, el Abogado General ha dictado sus conclusiones al respecto, con fecha de 30 de junio de 2016. El TJUE se ha pronunciado en la sentencia de 1 de octubre de 2016 (asunto C-424/15) y el TS en la sentencia de 3 de noviembre de 2016 (rec. n 77/2016). A estas y otras cuestiones dedicamos este trabajo.

cesados antes de la expiración de su mandato por exigencia de un nuevo marco legal que crea un órgano de supervisión en el que se agrupan diversas autoridades nacionales de reglamentación de sectores regulados? Dicho cese anticipado, por la mera entrada en vigor de una nueva ley nacional y no por la pérdida sobrevenida de las condiciones personales de sus titulares que fueron establecidas de antemano en el derecho nacional, ¿puede considerarse compatible con lo dispuesto en el artículo 3, apartado 3 bis, de la Directiva 2002/21/CE?."

16 Resaltamos la ponencia que presentó JIMÉNEZ-BLANCO CARRILLO DE ALBORNOZ en unas Jornadas "Administraciones Públicas ante las reformas" celebradas en Baeza, el 9 de septiembre 2015, en relación al Auto del TS de 3 de julio de 2015.

17 Téngase en cuenta que la redacción del presente artículo es anterior a las citadas sentencias del TJUE y del TS y por ello no se incluye un estudio pormenorizado de las mismas.

18 Téngase en cuenta que en la actualidad está derogado su capítulo II por la Ley 3/2013, de 4 de junio, de creación de la Comisión Nacional de los Mercados y la Competencia (letra h de la Disposición derogatoria).

19 Un estudio completo de la CNMC puede consultarse, entre otros: CARLÓN RUIZ, M., La Comisión Nacional de Mercados y de la Competencia, Aranzadi, 2014; GUILLÉN CARAMÉS, J., "Las competencias de la Comisión Nacional de los Mercados y de la Competencia y las Autoridades autonómicas en la aplicación del Derecho de la competencia", Estudios de Deusto: revista de la Universidad de Deusto, Vol. 63, n. 1, 2015, p. p. 37-83. 


\section{EL FOMENTO DE LAS AUTORIDADES NACIONALES DE RE- GLAMENTACIÓN (ANRs) EN LA NORMATIVA EUROPEA DE 2009}

De partida resaltamos los cambios normativos sucedidos en Europa en el año 2009 en relación a las comunicaciones electrónicas y al sector de la energía (electricidad y gas ${ }^{20}$. En el ámbito de las comunicaciones electrónicas se trata del conocido tercer paquete de normas, también llamado paquete "telecom", aprobadas en noviembre de $2009^{21}$. En el sector de la energía nos referimos al tercer paquete normativo ${ }^{22}$ que abarca dos Directivas ${ }^{23}$ : la Directiva del Gas y la Directiva de la Electricidad, que debían ser adaptadas al ordenamiento interno de cada Estado miembro antes del 3 de marzo de 2011, y tres Reglamentos ${ }^{24}$. De este modo, el tercer paquete de la energía contiene medidas para un funcionamiento adecuado del mercado teniendo en cuenta

$20 \mathrm{Al}$ respecto puede consultarse, entre otros, el libro colectivo publicado en español y alemán DARNACULLETA I GARDELLA, M.M., ESTEVE PARDO, J. y SPIECKER G. DÖHMANN (Dirs.), Estrategias del Derecho ante la incertidumbre y la globalización", Marcial Pons, 2015; DARNACULLETA I GARDELLA, M.M., ESTEVE PARDO, J. y SPIECKER G. DÖHMANN (Hrsg.), Strategien des Rechts im Angesidef von Ungenissheit und globalisieeung, Nomos, 2015. En particular los trabajos siguientes: MARTI DEL MORAL, A., "La neutralidad política de los expertos en las autoridades reguladoras y la cooperación europea en el mercado interior del gas y de la electricidad", p.p. 119-136, en el libro español; "Die oolitische Neutralität von Experten bei regulierenchen Bechörden und die europäische cooperatrion im gas- und Strombinnenmarkt" p.p. 132-154, en el libro alemán; DE LA TORRE MARTÍNEZ, L., "El fomento de la neutralidad política de los expertos y la cooperación transnacional de entidades reguladoras. La regulación europea en materia de comunicaciones electrónicas", p.p. 103-118, en el libro español; "Fördesung der politischen Neutralitatät von Experten un transnationales kooperation von aufsicisbeliorden. Die europäische Reguliierung im Bereich der electronischen kommunikation”, p.p. 112-131, en el libro alemán.

21 El nuevo marco está compuesto por la Directiva 2009/136/CE, del Parlamento Europeo y del Consejo, de 25 de noviembre de 2009, por la que se modifican varias Directivas de 2002; la Directiva 2009/140/CE, del Parlamento Europeo y del Consejo, de 25 de noviembre de 2009, por la que se modifican la Directiva 2002/21/CE y otras normas; y el Reglamento (CE) número 1211/2009 del Parlamento Europeo y del Consejo, por el que se establece el Organismo de Reguladores Europeos de las Comunicaciones electrónicas (ORECE) y la Oficina.

22 Comunicación de la Comisión de 10 de enero de 2007, "Una política energética para Europa".

23 Directiva 2009/72/CE, del Parlamento Europeo y del Consejo, de 13 de julio de 2009, sobre normas comunes para el mercado interior de la electricidad y por la que se deroga la Directiva 2003/54/ CE; Directiva 2009/73/CE, del Parlamento Europeo y del Consejo, de 13 de julio de 2009, sobre normas comunes para el mercado interior de gas natural y por la que se deroga la Directiva 2003/55/CE, publicadas en el DOCE L num. 211 de 14 agosto 2009, con entrada en vigor el 3 septiembre de 2009.

${ }_{24}$ Reglamento (CE) núm. 713/2009 del Parlamento Europeo y del Consejo, de 13 de julio de 2009, por el que se crea la Agencia de Cooperación de los Reguladores de la Energía; Reglamento (CE) núm. 715/2009, del Parlamento Europeo y del Consejo, de 13 de julio de 2009 sobre las condiciones de acceso a las redes de transporte de gas natural y por el que se deroga el Reglamento (CE) núm. 1775/2005; Reglamento CE núm. 714/2009 del Parlamento Europeo y del Consejo de 13 de julio de 2009 relativo a las condiciones de acceso a la red para el comercio transfronterizo de electricidad y por el que se deroga el Reglamento (CE) no 1228/2003, DOCE L núm. 211 de 14 agosto 2009. 
la desconcentración y separación de las redes, el fortalecimiento de la independencia y de las competencias que ostentan las $\mathrm{ANR}^{25}$. Todo ello pretende conseguir una mejora de los mercados de los usuarios finales de los que se benefician los consumidores ${ }^{26}$.

Desde un punto de vista institucional, en virtud del paquete normativo, se sustituye el Grupo de Reguladores Europeos ERGEG, creado en 2003, por la "Agencia Europea para la Cooperación de los Reguladores de la Energía” (ACER) y por ello se constituye un nuevo marco para la cooperación de las Autoridades Reguladoras Nacionales entre ellas y con la Comisión Europea. Por tanto, este conjunto normativo incide en la organización y funcionamiento de las ANRs cada vez de forma más profunda, ahondando en asuntos de organización propia de los Estados miembros ${ }^{27}$ y de las instituciones europeas.

En materia de gas y electricidad, la regulación de 2009 prevé que las ANRs se integren de un grupo de expertos o personas de reconocido prestigio y experiencia profesional en los mercados, y sea un órgano asesor y consultor que elabore informes y dictámenes; también se les reconocen algunos poderes decisorios en determinadas materias, según prevén los arts. 6 a 9 del Reglamento 713/2009. La normativa europea sobre energía de 2009 pone de manifiesto las características que diseñan un cierto modelo de regulación económica ${ }^{28}$ y una forma concreta de organización administrativa $^{29}$.

En consecuencia, las medidas que se establecen en la citada normativa europea de energía se pueden agrupar, de forma breve, en dos: de un lado, en lo referente a las ANRs, subrayamos el fomento de neutralidad política e independencia en la

${ }_{25}$ En el ámbito nacional, en materia de energía, señalamos, entre otros: SERRANO GONZÁLEZ, M., "La Comisión Nacional de Energía", Tratado de regulación del sector eléctrico, coordinado por SALA ARQUER, J.M, y otros, Vol. 1, 2009 (Aspectos jurídicos), p. p. 267-287, y de la misma autora: "La Comisión Nacional de Energía (CNE) como regulador de los sectores energéticos. Relaciones y delimitación de competencias entre el regulador y la Administración general, Derecho de la regulación económica, MUÑOZ MACHADO, S., ESTEVE, J., (dir.), Vol. 3, Tomo 1, 2010 (Sector energético), p. p. 79-124.

26 JIMÉNEZ-BLANCO CARRILLO DE ALBORNOZ, A, "La reforma de la Ley del Sector Eléctrico para su adaptación a las exigencias de las directivas comunitarias", Tratado de regulación del sector eléctrico, vol. 1, 2009 (Aspectos jurídicos), p. p. 241-266.

27 BACIGALUPO SAGGESE, M, "La Unión Europea y las autoridades reguladoras de la energía", Revista de Derecho de la Unión Europea, n. 16, 2009, p.p. 185-194; también "Los reguladores nacionales de la energía en las nuevas directivas del tercer paquete energético de la Unión Europea: independencia y funciones", Revista de derecho de la competencia y la distribución, n. 6, 2010, págs. 145-152.

${ }_{28}$ ESTEVE PARDO, J., "El encuadre de la regulación de la economía en el derecho público", en MUÑOZ MACHADO, S. y ESTEVE PARDO, J., Fundamentos e instituciones de la regulación, Derecho de la regulación económica, tomo I, Iustel, 2009, p. 387 y ss.

29 VIDA FERNÁNDEZ, J., "El condicionamiento de la organización administrativa de los Estados miembros por la política comunitaria de telecomunicaciones" en E. GÓMEZ REINO Y CARNOTA (Coord.), Telecomunicaciones, infraestructuras y libre competencia, Valencia: Tirant lo Blanch, 2004, p. 
ejecución de la normativa europea frente a las intrusiones internas derivadas de otros entes públicos y partidos políticos y frente a las injerencias externas que procedan de los operadores del mercado; y, de otro lado, a nivel europeo, se crea una Agencia europea, la Agencia de Cooperación de los Reguladores de la Energía (ACER), a la que se dota de una cierta independencia frente a los Estados miembros y a las propias instituciones comunitarias (Comisión), lo que se lleva a cabo por primera vez en la organización administrativa europea del mercado de la energía.

Por su parte, en el ámbito de las comunicaciones electrónicas, en 2009 se aprueba el llamado paquete "telecom" de 2009, como ya hemos indicado, que modifica parcialmente la Directiva Marco y pretende establecer "(...) un marco armonizado para la regulación de los servicios de comunicaciones electrónicas, (...). Fija las misiones de las autoridades nacionales de reglamentación e instaura una serie de procedimientos para garantizar la aplicación armonizada del marco regulador en toda la Comunidad" (art. 1.1 Directiva Marco 140/2009). Dentro de los objetivos y de los medios que establecen las normas europeas de comunicaciones electrónicas de $2009^{30}$ resaltamos, al menos, tres novedades que afectan a las formas de intervención de las autoridades europeas y nacionales que han de regular el mercado:

1) Se produce un aumento significativo de poder de la Comisión Europea, a la cual se le otorgan nuevas responsabilidades relativas a la imposición y a la aplicación de medidas correctoras a los reguladores nacionales, con el fin de lograr una aplicación coherente de las normas europeas (sirvan de ejemplos los arts. 7 y 19 de la Directiva Marco 140/2009 ${ }^{31}$.

145 y ss; JIMÉNEZ-BLANCO CARRILLO DE ALBORNOZ, A., "Organización administrativa y relaciones interadministrativas", Documentación Administrativa: Nueva Época, n. 2, 2015.

30 La Directiva 136/2009 y la Directiva 140/2009 y el Reglamento 1211/2009 del Parlamento Europeo y del Consejo de 25 de noviembre de comunicaciones electrónicas.

31 Véase el artículo 7 relativo a la consolidación del mercado interior en materia de comunicaciones electrónicas, en especial los apartados 5 y 6: “(...) la Comisión podrá: a) tomar la decisión de instar a la autoridad nacional de reglamentación afectada a que retire el proyecto de medida, y/o; b) adoptar una decisión retirando sus reservas sobre el proyecto a que se refiere el apartado 4. La Comisión tendrá en cuenta en la mayor medida posible el dictamen de ORECE antes de adoptar la decisión. Se adjuntará a la decisión un análisis detallado y objetivo de las razones por las que la Comisión considera que el proyecto de medida no debería adoptarse, junto con propuestas específicas de modificación del proyecto de medidas. Apartado 6. En caso de que la Comisión haya adoptado una decisión con arreglo al apartado 5, por la que se requiere de la autoridad nacional de reglamentación la retirada de un proyecto de medida, la autoridad nacional de reglamentación modificará o retirará el proyecto de medida en el plazo de seis meses a partir de la fecha de la decisión de la Comisión. (...)".

También sirve de ejemplo el artículo 19, apartados 1, 2 y 3, de la Directiva marco relativo a los procedimientos de armonización. En este caso, “(...) cuando la Comisión constate que las divergencias en la ejecución por las autoridades nacionales de reglamentación de las tareas reguladoras especificadas en la presente Directiva y en las Directivas específicas pueden crear un obstáculo al mercado interior, podrá presentar, teniendo en cuenta en la mayor medida posible el dictamen del ORECE, una recomendación o 
2) Se fortalecen los poderes reguladores de las ANRs y se fomenta su independencia frente a las eventuales distorsiones políticas y frente a los operadores del mercado para actuar en beneficio de los usuarios (art. 3 apartados 3, 3 bis, 3 ter y 3 quater Directiva Marco 140/2009)32. En particular, el artículo 3, apartado 3 de la citada Directiva expresa que: "Los Estados miembros velarán por que las autoridades nacionales de reglamentación ejerzan sus competencias con imparcialidad, transparencia y a su debido tiempo. Los Estados miembros velarán por que las autoridades nacionales de reglamentación dispongan de recursos financieros y humanos adecuados para desempeñar las tareas que se les hayan asignado." En este sentido la Directiva 140/2009 contempla que: "Tal influencia exterior hace que un órgano legislativo nacional resulte inadecuado para actuar como autoridad nacional de reglamentación con arreglo al marco regulador" (Apartado 13 de la Directiva 140/2009). Esta declaración afecta al concepto propio de ANR que permite una pluralidad de organismos de regulación y que es nueva en el Derecho europeo.

En Alemania, la Agencia Federal de redes de Electricidad, Gas, Telecomunicaciones, Correos y Ferrocarriles es la Autoridad Nacional de Reglamentación. Comenzó a funcionar con el nombre de autoridad reguladora de las telecomunicaciones y correos hasta el 1 enero de 1998. Con la aceptación de la regulación del mercado de la electricidad y del gas fue renombrada a partir del 18 de julio 2005 y desde el 1 de enero de 2006 es competente también para la regulación de la red ferroviaria.

decisión sobre la aplicación armonizada de lo dispuesto en la presente Directiva y en las Directivas específicas para fomentar la consecución de los objetivos enunciados en el artículo 8" (apartado 1). Además, en "los casos en que la Comisión emita una recomendación con arreglo al apartado 1, actuará de conformidad con el procedimiento consultivo contemplado en el artículo 22, apartado 2. (...) (apartado 2). Finalmente la Directiva señala que sólo determinadas decisiones, las adoptadas de conformidad con el apartado 1, podrán incluir únicamente la identificación de un planteamiento armonizado o coordinado con objeto de abordar determinadas cuestiones (apartado 3).

32 En el artículo 3, apartado 3 se afirma que "3 bis. (...), las autoridades nacionales de reglamentación encargadas de la regulación ex ante del mercado o de la resolución de litigios entre empresas con arreglo a los artículos 20 y 21 de la presente Directiva actuarán con independencia y no solicitarán ni aceptarán instrucciones de ningún otro organismo en relación con la ejecución de las tareas que les asigne la legislación nacional por la que se aplique el Derecho comunitario. Esto no impedirá la supervisión de conformidad con el Derecho constitucional nacional. (...) 3 ter. Los Estados miembros velarán por que sus respectivas autoridades nacionales de reglamentación apoyen activamente los objetivos del ORECE de promover una mayor coordinación y coherencia reguladora. 3 quater. Los Estados miembros velarán por que, al adoptar sus propias decisiones para sus mercados nacionales, las autoridades nacionales de reglamentación tengan muy en cuenta los dictámenes y posiciones comunes adoptados por el ORECE.”. 
En España, según dispone el art. 68 de la Ley 9/2014, de 9 de mayo General de Telecomunicaciones ${ }^{33}$, son ANRs de telecomunicaciones: el Gobierno, los órganos superiores y directivos de determinados Ministerios, la Comisión Nacional de los Mercados y la Competencia ${ }^{34}$, y en el propio Anexo de la Ley se define el concepto de $\mathrm{ANR}^{35}$. Esta situación que se deriva de las normas europeas de 2009 de comunicaciones electrónicas es parecida, pero no idéntica, al papel que se otorgan a las ANR

33 Sobre la Ley General de Telecomunicaciones también encontramos numerosos trabajos, entre otros: CARLÓN RUIZ, M., "Reordenación de las competencias regulatorias en relación con el mercado de las comunicaciones electrónicas a resultas de la aprobación de las leyes 3/2013, de creación de la CNMC, y 9/2014, General de Telecomunicaciones", CARLÓN RUIZ, M. (Dir.), La Comisión Nacional de los Mercados y la Competencia, 2014, p. p. 299-364; PUYOL MONTERO, J., "Algunas consideraciones sobre la Ley 9/2014, de Telecomunicaciones", Iuris: Actualidad y práctica del derecho, n. 216, 2014, p. p. 16-19; DE LA QUADRA-SALCEDO Y FERNÁNDEZ DEL CASTILLO, T., (Dir.) y VIDA FERNÁNDEZ, J. (Coord.), Derecho de las telecomunicaciones adaptado a la Ley 9/2014, de 9 de mayo, General de Telecomunicaciones, Thomson Reuters-Civitas, 2015; LUCAS TOBAJAS, A. B., "La Ley 9/2014, de 9 de mayo, general de Telecomunicaciones: el último desafío", Revista General de Derecho Administrativo, Iustel, n. 39, 2015; PÉREZ, D., "Breve reseña sobre la Ley española 9/2014, General de Telecomunicaciones", Revista Digital de Derecho Administrativo, n. 14, 2015, p. p. 259-277.

34 Sobre Administraciones Independientes en España, y la Comisión del Mercado de las Telecomunicaciones (aunque como ya sabemos tras la Ley de Telecomunicaciones de 9 de mayo de 2014, la Comisión del Mercedo de las Telecomunicaciones se ha suprimido y ha asumido las funciones la Comisión Nacional de los Mercados y la Competencia) pueden consultarse: SALA ARQUER, J. M., "El Estado neutral: contribución al estudio de la Administraciones independientes", REDA n. 42, 1984, p. p. 401-422; LÓPEZ RAMÓN, F., "El Consejo de Seguridad Nuclear: un ejemplo de Administración independiente", RAP n. 124, 1991, p. p. 189 y ss, también publicado en La Administración instrumental. Homenaje a M. Clavero Arévalo, Civitas, tomo I, 1994, p. p. 575-597; POMED SÁNCHEZ, L. A., "Fundamento y naturaleza jurídica de las Administraciones independientes", RAP, n. 132, 1993, p. p. 117 y ss; GARCÍA LLOVET, E., "Autoridades administrativas independientes y Estado de Derecho", RAP, n. 131, 1993, p. p. 61 y ss; BETANCOR RODRÍGUEZ, A., Las Administraciones independientes. Un reto para el Estado social y democrático de Derecho, Tecnos, 1994; FERNÁNDEZ RODRÍGUEZ, T.R., "Reflexiones sobre las llamadas Administraciones independientes", La Administración instrumental. Homenaje a M. Clavero Arévalo, Civitas, tomo I, 1994, p. p. 427 y ss; S. MUÑOZ MACHADO, Servicio público y mercado. Las telecomunicaciones, Civitas, Madrid, 1997; A. BETANCOURT, Las Administraciones independientes, Tecnos, Madrid, 1997; J. M. SALA ARQUER, La Comisión del Mercado de las Telecomunicaciones, Civitas, Madrid, 2001; A. MARTI DEL MORAL, La Comisión del Mercado de las Telecomunicaciones, INAP, Madrid, 2001, p. 5 y ss; J. VIDA FERNÁNDEZ, "El condicionamiento de la organización administrativa de los Estados miembros por la política comunitaria de telecomunicaciones", en: E. GÓMEZ REINO Y CARNOTA (Coord.), Telecomunicaciones, infraestructuras y libre competencia, Tirant lo Blanch, Valencia, 2004, p. 145 y ss; J. C. LAGUNA DE PAZ, Telecomunicaciones: regulación y mercado, Thomson-Aranzadi, Pamplona, 2007; MUÑOZ MACHADO, S., y ESTEVE PARDO, J., (Coords.), Fundamentos de la regulación económica, Derecho de la regulación económica, tomo I, Iustel, Madrid, 2009, p. 899 y ss; COSCULLUELA MONTANER, L., LOPEZ BENITEZ, M., Derecho público económico, 2012, p. p. 222 y ss

35 El Anexo de la Ley de Telecomunicaciones de 2014, en el punto 6, define Autoridad Nacional de Reglamentación: "el Gobierno, los departamentos ministeriales, órganos superiores y directivos y organismos públicos, que de conformidad con esta Ley ejercen las competencias que en la misma se prevén”. Un análisis detenido de la normativa general de telecomunicaciones en España puede consultarse en: E. GARCÍA DE ENTERRÍA/T. DE LA QUADRA SALCEDO (Coords.), Comentario a la Ley General de Telecomunicaciones, Ley 32/2003, de 3 de noviembre, Thomson-Civitas, Madrid, 2004; T. DE LA QUADRA SALCEDO (Dir.), IV. Telecomunicaciones, en la colección Derecho de la regulación económica, Iustel, Madrid, 2009. 
en materia de energía y electricidad, según disponen las Directivas aplicables en esas materias. Atendiendo al concepto de ANR, si bien acabamos de decir que se admite una pluralidad de ANRs en materia de comunicaciones electrónicas, las Directivas de 2009 del gas y de la electricidad establecen que la ANR ha de ser única. Constituye una novedad la designación de una única autoridad reguladora a escala nacional (art. 39.1 Directiva 73/2009), sin perjuicio de la designación de otras autoridades reguladoras a escala regional en los Estados miembros, siempre que haya un representante a los fines de representación y contactos en el nivel comunitario en el seno del Consejo de Reguladores de la Agencia de Cooperación de los Reguladores de la Energía.

Teniendo en cuenta la legislación española, resaltamos el papel que ha tenido en esta materia la Ley 2/2011, de 4 de marzo, de Economía Sostenible (LES en adelante), que llevó a cabo una regulación propia y especial para los seis organismos reguladores existentes en esos momentos, con especial atención a garantizar su independencia respecto de los agentes del mercado. En particular, el Capítulo II del Título I, que recogía la regulación sobre los "Organismos Reguladores", y la Disposición final cuarta relativa al "Organismo regulador del sector transporte" Estas previsiones normativas han sido derogadas por la Ley 3/2013, de 4 de junio, de creación de la Comisión Nacional de los Mercados y la Competencia (letra h de la Disposición derogatoria). Además, hay que tener en cuenta la Ley 40/2015, de 1 de octubre, de Régimen Jurídico del Sector Público que regula las autoridades administrativas independientes de ámbito estatal ${ }^{37}$. En particular define a dichas autoridades administrativas como "entidades de derecho público que, vinculadas a la Administración General del Estado y con personalidad jurídica propia, tienen atribuidas funciones de regulación o supervisión de carácter externo sobre sectores

36 La composición de las ANRs en los Estados miembros en la LES venía determinada por la elección de "personas de reconocido prestigio y competencia profesional" por parte del Gobierno, previa comparecencia ante "la Comisión correspondiente del Congreso de los Diputados, que versará sobre la capacidad de los candidatos" (art. 13.1 de la Ley 2/2011 de 4 de marzo de Economía Sostenible cuya Disposición Final $34^{\circ}$ fue modificada por el art. 48 de la Ley General de Telecomunicaciones de 2003). De otra parte, la LES establecía una serie de garantías para la independencia de los miembros de los Organismos Reguladores, como son el sometimiento "al régimen de incompatibilidades de los altos cargos de la Administración" (art. 15.3 LES), y la prohibición durante los dos años posteriores a su cese, "de ejercer actividad profesional privada alguna relacionada con el sector regulado, tanto en empresas del sector como para empresas del sector", en el caso de los Organismos Reguladores (art. 15.4 LES).

37 GALÁN VIOQUE, R. R., "A vueltas con la regulación de la responsabilidad del Estado legislador. Un nuevo intento introducido en el Proyecto de Ley de Régimen jurídico del sector público de limitar el alcance de la responsabilidad del Estado Legislador, esta vez en su vertiente", Documentación Administrativa: Nueva Época, n. 2, 2015. 
económicos o actividades determinadas, por requerir su desempeño de independencia funcional o una especial autonomía respecto de la Administración General del Estado, lo que deberá determinarse en una norma con rango de Ley". Estas autoridades administrativas independientes "actuarán, en el desarrollo de su actividad y para el cumplimiento de sus fines, con independencia de cualquier interés empresarial o comercial" y estarán sujetas al principio de sostenibilidad financiera $(\text { art. } 109 \text { y } 110)^{38}$.

La introducción de la participación de los expertos en el conocimiento de los asuntos dentro de la Administración pública se ha realizado de forma tradicional mediante la fórmula clásica de los órganos consultivos y asesores ${ }^{39}$. Si bien esto es así, con la creación de las autoridades administrativas independientes ${ }^{40}$ integrada

38 En todo caso, la doctrina discute sobre la naturaleza de las autoridades reguladoras nacionales y su relación con los poderes legislativo y ejecutivo considerados al modo tradicional, si bien la explicación razonable deriva de un nuevo planteamiento, pues se trata de entes públicos con poderes normativos que responden a un nuevo concepto de regulación económica. J. ESTEVE PARDO, "El encuadre de la regulación de la economía en el derecho público", en: S. MUÑOZ MACHADO/J. ESTEVE PARDO, Fundamentos e instituciones de la regulación, op. cit., p. 387 y ss.

39 Sobre la valoración del componente experto y el control judicial de la CMT pueden consultarse, entre otros, los trabajos en la obra colectiva coordinados por DE LA QUADRA-SALCEDO, Telecomunicaciones, Derecho de la regulación económica, op. cit.; SÁNCHEZ BLANCO, M., y SOLER MATUTES, P., "Autoridades de reglamentación y telecomunicaciones: las organizaciones públicas y su regulación. Especial referencia a la Comisión del Mercado de las Telecomunicaciones", en: S. MUÑOZ MACHADO (Coord.), Derecho de la regulación económica, vol. 4, Iustel, Madrid, 2010, p. 187 y ss.

40 La actividad de las ANRS no es la propia del legislador nacional ni tampoco las funciones propias de un poder ejecutivo tradicional. Se trata de entes públicos con poderes normativos que responden a un nuevo concepto de regulación económica, cuya implantación no es fácil. ESTEVE PARDO, J., "El encuadre de la regulación de la economía en el derecho público", en MUÑOZ MACHADO, S. y ESTEVE PARDO, J., Fundamentos e instituciones de la regulación, Derecho de la regulación económica, tomo I, Iustel, 2009, p. 387 y ss. Por ello que algunos autores entienden que esta concreta forma de organización constituye un elemento necesario de la regulación. Sin embargo, la doctrina considera mayoritariamente que la organización del sujeto regulador en forma de autoridad independiente es un elemento accesorio y no constitutivo de la función de regulación. DARNACULLETA I GARDELLA, M. M., "La recepción y desarrollo de los conceptos y fórmulas de la regulación. El debate en la República Federal Alemana", Derecho de la regulación económica. Fundamentos e instituciones de la regulación, tomo I, 2009, p. 366 y ss. 
por expertos que ejercen potestades administrativas y otras de carácter regulador se rompe esta dinámica ${ }^{41}$.

\section{3) Se crea el ORECE ${ }^{42}$ y la Oficina ${ }^{43}$, como un organismo de cooperación}

${ }^{41}$ Según M. M. DARNACULLETA I GARDELLA, "Se trata de entidades cuya legitimación se basa principalmente en el supuesto carácter experto de sus miembros, en la neutralidad de sus decisiones y en su independencia del Gobierno. Es por ello que algunos autores entienden que esta concreta forma de organización constituye un elemento necesario de la regulación. Sin embargo, la doctrina considera mayoritariamente que la organización del sujeto regulador en forma de autoridad independiente es un elemento accesorio y no constitutivo de la función de regulación", en: M. M. DARNACULLETA I GARDELLA, Derecho público y autorregulación: la autorregulación regulada, Marcial Pons, Madrid-Barcelona, 2005; Sobre la autoridad reguladora de las telecomunicaciones M. M. DARNACULLETA I GARDELLA, "La recepción y desarrollo de los conceptos y fórmulas de la regulación. El debate en la República Federal Alemana", en: S. MUÑOZ MACHADO/J. ESTEVE PARDO, Fundamentos e instituciones de la regulación, op. cit., p. 349 y ss, y p. 366.

42 Un elemento esencial del nuevo marco normativo europeo de 2009 es la creación del ORECE y de la Oficina. La necesidad de crear este Organismo se justifica en la fragmentación de la reglamentación, como resultado de una falta de coordinación entre las actividades de las ANRs, lo cual, puede poner en peligro la competitividad del sector y perjudicar a los usuarios por la ausencia de una competencia transfronteriza efectiva (Directiva 140/2009, considerando $2^{\circ}$ ). Además, la creación de este organismo europeo ha de satisfacer el cumplimiento de los principios de subsidiariedad y proporcionalidad del artículo 5 del Tratado y de ello se ocupa el Reglamento 1211/2009. El ORECE no es una "agencia europea del mercado de las telecomunicaciones", como se pretendió en un primer momento en la propuesta de Reglamento del año 2007 por la Comisión. Las instituciones europeas, tras varios años de debates, coinciden en la necesidad de crear el ORECE, mediante el Reglamento (CE) n ${ }^{\circ}$ 1211/2009 del Parlamento Europeo y del Consejo, de 25 de noviembre de 2009, que entró en vigor el 7 de enero de 2010 y comenzó sus actividades el 28 de enero de 2010 con la primera reunión del Consejo de Reguladores y del Comité de Gestión de la Oficina en Bruselas. De este modo, la razón de ser del ORECE radica en su funcionamiento como grupo de expertos que "debe actuar como punto de referencia y generar confianza en virtud de su independencia, la calidad de su asesoramiento e información, la transparencia de sus procedimientos y métodos de funcionamiento, y su diligencia en el desempeño de sus tareas" (Considerando $6^{\circ}$ del Reglamento 1211/2009). El ORECE ha sustituido al "Grupo de Reguladores Europeos de las Telecomunicaciones" ERG (creado por la Comisión por la Decisión 2002/627/CE). La Decisión de 21 de mayo de 2010 suprime el ERG desde el 1 de junio de 2010, ya que, el ORECE debe actuar (según expresa el Considerando $6^{\circ}$ del Reglamento 1211/2009) como un foro exclusivo para la cooperación de las ANRs entre sí y entre las ANRs y la Comisión en el ejercicio de sus responsabilidades con arreglo al marco regulador europeo.

43 El papel fundamental del ORECE y la Oficina en la nueva regulación europea se puede sintetizar en varias observaciones: Una. El ORECE "no debe ser ni una agencia de la Comunidad ni tener personalidad jurídica". Se trata de un grupo de expertos que "debe reemplazar al Grupo de entidades reguladoras europeas y actuar como un foro exclusivo para la cooperación entre las ANR entre sí y entre las ANR y la Comisión en el ejercicio de todas sus responsabilidades con arreglo al marco regulador de la UE. Debe actuar como punto de referencia y generar confianza en virtud de su independencia, la calidad de su asesoramiento e información, la transparencia de sus procedimientos y métodos de funcionamiento, y su diligencia en el desempeño de sus tareas" (Considerando $6^{\circ}$ del Reglamento 1211/2009). En el ORECE participan los presidentes de los 27 reguladores de la Unión Europea y su actividad está organizada en grupos de trabajo formados por expertos de los reguladores nacionales; Dos. El ORECE se constituye como órgano oficial consultivo de la Comisión y como se desprende de los arts. 1 a 3 (objetivos, tareas y funciones) del Reglamento; se trata de una entidad de cooperación de naturaleza consultiva y asesora, sin potestad decisoria (art. 1.3 y art. 1.4 Reglamento); Tres. El OREGE se integra sólo por un Consejo de Regu- 
estrecha entre la Comisión y las ANRs y de éstas entre sí tratando de disminuir las incoherencias detectadas y ya señaladas en la aplicación de la normativa europea por los distintos Estados miembros a situaciones similares ${ }^{44}$.

\section{EL FORTALECIMIENTO DE LA INDEPENDENCIA DE LAS ANRs EN LA NORMATIVA EUROPEA DE 2009}

Como hemos avanzado al inicio, las ideas de liberalización y privatización de empresas y servicios conllevan una cierta "desideologización de la política económica”, con el propósito de lograr una mejora de las prestaciones a favor de los usuarios finales. De este modo, la idea de la neutralidad o independencia surge en el ámbito del sector bancario con la creación del Sistema de Bancos Centrales Europeos, prevista en el Tratado de la Unión Europea (en la versión de Maastricht aprobada en 1992 $)^{45}$. GARCÍA DE ENTERRÍA ha subrayado que el SEBC quiebra la regla general conforme a la cual la responsabilidad de los Estados miembros abarca la totalidad de la acción de sus órganos, pues se reconoce al SEBC una acción procesal directa contra organismos públicos de los Estados miembros ${ }^{46}$.

Las ideas de liberalización y privatización, por tanto, pretenden "desideologizar la política económica" y atender a la "mejora de los servicios y las prestaciones".

ladores, compuesto por un representante de cada Estado miembro, que será el director de la ANR (art. 4.1 del Reglamento 1211/2009); Cuarto. El Reglamento 1211/2009 garantiza la independencia del ORECE instaurando un conjunto de técnicas de garantías orgánica (art. 4.10 Reglamento 1211/2009), funcional y personal (arts. 4.2, 4.4 y 4.5, y art. 21 del Reglamento 1211/2009); Quinto. La Oficina, que se crea por el mismo Reglamento (CE) n n $^{\circ} 1211 / 2009$, es un organismo europeo con personalidad jurídica y posee autonomía jurídica, administrativa y financiera. Está compuesta por un Comité de gestión y un Director administrativo (art. 8 Reglamento).

44 La falta de uniformidad en la interpretación del Derecho europeo, como sucede en materia de las Directivas de las comunicaciones electrónicas, se demuestra en la disparidad de criterios entre las autoridades nacionales de reglamentación y la Comisión Europea en diversas cuestiones sobre los que se ha pronunciado el TJCE, como ha sucedido en la Sentencia del TJCE de 3 de diciembre de 2009, Asunto C-424/07, la Comisión Europea contra la República Federal de Alemania. Es necesario que exista una mayor cooperación entre las ANRs y la Comisión Europea.

45 Sobre el Banco Central Europeo, MANGAS MARTÍN, A., LIÑAN, D., Instituciones y Derecho de la Unión Europea, Tecnos, 2009, p. 287-308; los autores aluden a la independencia y la legitimidad democrática de sus decisiones, p. 303 y ss. Con anterioridad, FERNÁNDEZ RODRÍGUEZ, T.R., "La autonomía de los bancos centrales: un problema de rango constitucional", Estudios de Derecho bancario y bursátil, Vol. 1, 1994, p. p. 715-738; JIMÉNEZ-BLANCO CARRILLO DE ALBORNOZ, A, "Funciones y competencias del Banco de España”, Derecho del mercado financiero, coord. J. MARTÍNEZ-SIMANCAS, A. ALONSO, vol. 1, tomo 2, 1994, p. p. 215-230.

46 GARCÍA DE ENTERRÍA, E., "La unión monetaria según Maastricht y su significado", Cuenta y razón del pensamiento actual, n. 71/72, 1992, p. 20. Resulta imprescindible en esta materia consultar la colección de libros Coordinada por MUÑOZ MACHADO en los diversos sectores económicos, transportes, audiovisual, mercado de valores, sistema bancario, etc. En particular, MUÑOZ MACHADO, S., y ESTEVE PARDO, S., Fundamentos e instituciones de la regulación, Iustel, 2009. 
MALARET GARCÍA ha puesto de relieve que el papel central del mercado común “parece permitir la 'despolitización' del proceso frente a un modelo de regulación estatal clásico en el que las divergencias nacionales e ideológicas se hubieran presentado con toda su nitidez. En esta dinámica, las reglas a adoptar, las normas a formular serán meras exigencias 'técnicas' para garantizar las libertades y la competencia. Por ello, sus actores privilegiados en el panorama institucional comunitario serán la Comisión y el Tribunal de Justicia, instancias que se presentan como desvinculadas de los órganos políticos nacionales". Además, entiende que la decisión que implica la despolitización no elimina las discusiones de carácter político. Éstas se elevan de escala, y han de ser valoradas y resueltas por los órganos comunitarios que van a adquirir, por tanto, cada vez mayor importancia desde el punto de vista político ${ }^{47}$.

Es posible afirmar que el recurso a la "despolitización” es el resultado también del principio de separación de actividades en las telecomunicaciones, exigiendo una independencia entre el regulador y los operadores, y la creación de entes públicos dotados de autonomía o independencia funcional respecto a los ejecutivos. Se trata de un efecto más de la "despolitización", que no está lejos de lo que SCHMITT entiende por garantizar una cierta neutralidad política en la gestión de determinadas decisiones públicas. En el sentido acuñado por SCHMITT, la neutralidad del experto es "la neutralidad sobre la base de un conocimiento objetivo y no egoísta de las cosas, es la propia del experto que dictamina y asesora, la del mediador y árbitro que no actúa como representante de intereses o exponente del sistema pluralista" ${ }^{48}$.

El otorgamiento de una autonomía real a las autoridades independientes de regulación es un fenómeno impulsado desde el ámbito del Derecho europeo, en particular por el propio Tratado de la Unión Europea, con el fin último de obtener la consecución de un mercado único. Por tanto, a nuestro juicio, este concepto fraguado en Europa no es coincidente con la teoría clásica de la neutralidad política en la Administración pública derivada de la legislación española ${ }^{49}$.

Las ANRs comenzaron su andadura de forma progresiva en cada Estado miembro por impulso de las Directivas de 2003, en concreto la Directiva 2003/55/ CE obligaba a los Estados miembros a establecer unos reguladores con competencias específicas. No obstante, la experiencia deja de manifiesto que la eficacia de la

${ }^{47}$ MALARET GARCÍA, E., "Servicios públicos, funciones públicas, garantías de los derechos de los ciudadanos: perennidad de las necesidades, transformación del contexto", RAP, 145, 1998, p. 78 y 79.

48 G. SCHMITT, El concepto de lo político, Alianza editorial, 2005, p. 129. También puede verse la reflexión que hace sobre los significados positivos y negativos del término "neutralidad política" en p. p. 125 y ss.

49 BETANCOR RODRÍGUEZ, A, "Puertas giratorias: regulación y control", La corrupción en España: ámbitos, causas y remedios jurídicos, VILLORIA, M., GIMENO, J.M., TEJEDOR, J., JIMÉNEZ, R., 2016, p. p. 157-184. 
regulación, con frecuencia, se ve obstaculizada por la falta de independencia de los reguladores respecto a los gobiernos, así como por la insuficiencia de los poderes y del margen discrecional de que gozan. Por este motivo, en su reunión de Bruselas de 8 y 9 de marzo de 2007, el Consejo Europeo invitó a la Comisión a preparar propuestas legislativas que estableciesen una mayor armonización de las competencias y fortalecimiento de la independencia de los reguladores nacionales de energía. El resultado es la aprobación de la normativa europea de 2009 ya comentada.

Así por ejemplo las Directivas del gas y de la electricidad garantizan la independencia de las $\mathrm{ANRs}^{50}$ mediante distintas técnicas que afectan a su funcionamiento, nombramiento y cese de los miembros de las ANRs, como es la limitación de las causas de cese de los miembros de las $\mathrm{ANRs}^{51}$. En este ámbito, el considerando $30 \mathrm{de}$ la Directiva del gas 73/2009 hace un planteamiento completo de la independencia y de sus controles que, por su interés, reproducimos:

"Es preciso, para un adecuado funcionamiento del mercado interior del gas natural, que los reguladores de la energía puedan tomar decisiones sobre todas las cuestiones de reglamentación pertinentes y que sean totalmente independientes de cualquier otro interés público o privado. Ello no impedirá un control jurisdiccional ni una supervisión parlamentaria conforme al Derecho constitucional de los Estados miembros. Además, la aprobación del presupuesto de los reguladores por el legislador nacional no es óbice para la autonomía presupuestaria. Las disposiciones relativas a la autonomía en la ejecución del presupuesto asignado a la autoridad reguladora nacional deben aplicarse en el marco definido por la legislación y la normativa presupuestarias nacionales. Al tiempo que contribuyen a la independencia de las autoridades reguladoras nacionales respecto de cualquier interés político o económico mediante un adecuado régimen de rotación, los Estados miembros deben poder tener debidamente en cuenta la disponibilidad de recursos humanos y el número de miembros del Consejo de Administración".

Por ello, resaltamos la importancia clave que adquiere aquí la independencia de las ANRs frente a las influencias políticas y de los operadores, lo que permite a los miembros de las ANRs ejercer las funciones como expertos de reconocido prestigio y adoptar las decisiones para lograr el mercado único europeo y garantizar la neutralidad política.

Tras exponer el fomento de las ANRs en la regulación europea, desde el propio Tratado y en las Directivas sectoriales comentadas, así como el fortalecimiento de la

$50 \quad$ Artículos 39 a 44 Directiva Gas 73/2009, especialmente el art. 39.4.

51 Artículo 39.5 Directiva Gas 73/2009. También el considerando 21 ${ }^{\circ}$ Directiva Gas 73/2009. 
independencia y neutralidad política que han de tener estos organismos reguladores, nos detenemos en el alcance que ha tenido la aplicación e interpretación de la citada independencia y neutralidad política de la normativa europea en el supuesto de que se cesen miembros de las ANRs antes de que expire el plazo y sin concurrir ninguna causa de las previstas en la legislación aplicable. Dicho de otro modo, tratamos de dilucidar si el cese de miembros de las ANRs, antes del plazo fijado en la normativa aplicable y sin mediar causa legal alguna, ha de interpretarse en el sentido de que estamos ante una injerencia a la citada independencia y neutralidad política o no.

\section{EL GESE DE MIEMBROS DE ANRs ANTES DEL PLAZO ESTABLECIDO Y FUERA DE LAS GASUSAS LEGALMENTE PREVISTAS}

\section{En materia de protección de datos.}

\subsection{Normativa aplicable.}

En este supuesto, analizamos las obligaciones derivadas del artículo 28.1, párrafo segundo, de la Directiva 95/46/CE del Parlamento Europeo y del Consejo, de 24 de octubre de 1995, relativa a la protección de las personas físicas en lo que respecta al tratamiento de datos personales y a la libre circulación de estos datos ${ }^{52}$, -según la cual debe garantizarse que cada autoridad de control ejerza con total independencia las funciones que le son atribuidas -, al poner fin antes de tiempo al mandato de la autoridad de control de la protección de datos personales ${ }^{53}$.

Por su parte, el Reglamento (CE) n n $^{\circ}$ /5/2001 del Parlamento Europeo y del Consejo, de 18 de diciembre de 2000, relativo a la protección de las personas físicas en lo que respecta al tratamiento de datos personales por las instituciones y los organismos comunitarios y a la libre circulación de estos datos ${ }^{54}$ crea una autoridad de control independiente denominada Supervisor Europeo de Protección de Datos (SEPD). Según dispone el artículo 42 de dicho Reglamento sobre el nombramiento, el Parlamento Europeo y el Consejo nombrarán de común acuerdo al SEPD por un mandato de cinco años, sobre la base de una lista elaborada por la Comisión como resultado de una convocatoria pública de candidaturas. Tal mandato del SEPD será

\footnotetext{
52 DO L 281, p. 31.

53 El artículo 28, apartado 1, párrafo segundo, de la Directiva 95/46 impone a los Estados miembros la obligación de instituir una o varias autoridades de control que ejercerán las funciones que les sean atribuidas con total independencia. La exigencia de control, por parte de una autoridad independiente, del cumplimiento de las normas de la Unión en materia de protección de las personas físicas respecto al tratamiento de datos personales se deriva también del Derecho primario de la Unión, en concreto del artículo 8, apartado 3, de la Carta de los Derechos Fundamentales de la Unión Europea y del artículo 16 TFUE, apartado 2 (apartado 47 de la sentencia).
}

54 DO 2001, L 8, p. 1. 
renovable. Aparte de la renovación periódica o de sustitución por motivo de fallecimiento, el mandato del SEPD llegará a su fin en caso de dimisión o de destitución. Además, el SEPD podrá ser destituido o desposeído de su derecho de pensión u otros privilegios equivalentes por el TJUE a petición del Parlamento Europeo, el Consejo o la Comisión si dejare de cumplir las condiciones necesarias para el ejercicio de sus funciones o hubiere cometido una falta grave.

\subsection{El caso de Hungría.}

Ahora nos detenemos en el caso de Hungría, en el que el TJUE ya ha tenido ocasión de pronunciarse en esta materia en la sentencia de 8 de abril de 2014. La Comisión Europea, conforme al artículo 258 TFUE, interpuso un recurso por incumplimiento ante el TJUE, solicitándole que declarara que Hungría había incumplido las obligaciones derivadas del artículo 28.1, párrafo segundo, de la Directiva 95/46/ $\mathrm{CE}^{55}$.

Centrándonos en el Derecho húngaro, la normativa de este país relativa a la autoridad de control -Ley de 1992- fue modificada con la entrada en vigor de la Ley de 1 de enero de $2012^{56}$, sobre autodeterminación en materia de información y libertad de información, que transpone al ordenamiento jurídico húngaro la Directiva 95/46. Esta Ley derogó la Ley de 1992 y, para sustituir al Supervisor, creó la Autoridad Nacional de Protección de Datos y Libertad de Información ${ }^{57}$.

En este contexto, el Supervisor húngaro, que contaba con un mandato de seis años, según la normativa húngara aplicable, cuando sólo llevaba tres años, fue cesado con la aprobación de la nueva regulación de Hungría en esta materia y se nombró otra figura, el presidente de la Autoridad, por un periodo de nueve años ${ }^{58}$.

Ante los requerimientos de la Comisión Europea, Hungría considera que el recurso por incumplimiento citado al principio es inadmisible, pues la sentencia por

${ }_{55}$ En este supuesto, un organismo que fue transformado en autoridad nacional de protección de datos y de libertad de información en 2012, y al frente de la cual el Gobierno húngaro colocó a Attila Péterfalvi por nueve año tras destituir al anterior supervisor, András Jori. Este había sido designado en 2008 por seis años y el fin de su mandato antes de tiempo fue recurrido por la Comisión Europea ante el TJUE por estimarla contraria a la Directiva europea de protección de datos.

${ }^{56} \quad$ En particular, la Ley n ${ }^{\circ}$ CXII de 2011.

${ }^{57}$ Nemzeti Adatvédelmi és Információszabadság Hatóság o Autoridad Nacional de Protección de Datos y Libertad de Información.

${ }_{58}$ El Sr. Jóri fue nombrado Supervisor el 29 de septiembre de 2008, en virtud de la Ley de 1992, y su entrada en funciones se produjo en esa misma fecha, con un mandato de seis años. Es decir, éste hubiera debido expirar a finales de septiembre de 2014. No obstante, terminó el 31 de diciembre de 2011, en aplicación del artículo 16 de las disposiciones transitorias de la Ley Fundamental. La Autoridad inició su actividad el 1 de enero de 2012 y, a propuesta del Primer Ministro, el Presidente de la República nombró al Sr. Péterfalvi como presidente de la Autoridad para un mandato de nueve años. 
la que se declarara el incumplimiento alegado no podría ejecutarse ${ }^{59}$. No obstante, la Comisión Europea rechaza las alegaciones de Hungría, y considera que el recurso sigue teniendo un objeto y nada se opone a la ejecución de una sentencia que declare la existencia del incumplimiento alegado.

Finalmente, el TJUE dictó sentencia el 8 de abril de 2014 y estimó, en contra de la decisión del Gobierno húngaro, que estas autoridades de control deben ejercer sus funciones sin ninguna influencia política externa. De este modo, el TJUE se pronunció con contundencia, advirtiendo que "el hecho de permitir a un Estado miembro poner fin al mandato de una autoridad de control antes de que expire, sin respetar las reglas y las garantías establecidas" es un modo "de injerencia". La sentencia del Tribunal de Luxemburgo, por tanto, obliga a Hungría a restablecer la legalidad, y de lo contrario, la Comisión Europea podría imponerle sanciones coercitivas ${ }^{60}$.

1.3. La exigencia de independencia incluye la obligación de respetar la duración del mandato de las autoridades de control hasta su expiración.

En particular, nos detenemos en los argumentos jurídicos ${ }^{61}$ que llevan al Tribunal europeo a adoptar la decisión que ya conocemos. De entrada, el Tribunal recuerda que la creación en los Estados miembros de autoridades de control independientes constituye un elemento esencial del respeto a la protección de las personas en lo que respecta al tratamiento de datos personales ${ }^{62}$.

$59 \quad$ A juicio de Hungría, suponiendo que el Tribunal de Justicia declarara que se ha puesto fin antes de tiempo al mandato del Supervisor infringiendo la Directiva 95/46, sólo sería posible subsanar tal ilegalidad destituyendo al presidente de la Autoridad y sustituyéndolo por el antiguo Supervisor, lo cual supondría repetir el incumplimiento alegado. Pues bien, según Hungría, la Comisión no puede solicitar al Tribunal de Justicia que dicte una sentencia que declare la existencia de un incumplimiento a la que el Estado miembro interesado sólo pueda atenerse infringiendo el Derecho de la Unión. Añade que el hecho de poner fin antes de tiempo al mandato del presidente de la Autoridad vulneraría del principio de independencia de la Autoridad sancionado por la Ley Fundamental. Además, según Hungría, la solución propuesta por la Comisión para subsanar el incumplimiento alegado, en caso de que se declarara su existencia, implicaría que todos los actos realizados por el presidente de la Autoridad fueran incompatibles con el Derecho de la Unión al haberse adoptado por una autoridad de control que no se ajusta a las exigencias de la Directiva 95/46, lo cual iría en contra del principio de seguridad jurídica. Hungría alega a este respecto que la Ley de 2011 responde, no obstante, a las exigencias de la Directiva 95/46.

60 Recordemos que el Gobierno húngaro ya se enfrentó a Bruselas al intentar poner fin al mandato del gobernador de su Banco Central y del Tribunal Constitucional del país. En estos casos dio marcha a atrás.

61 En particular, nos referimos a los apartados 47 a 62 de la sentencia.

62 Sentencias Comisión/Alemania, C-518/07, EU:C:2010:125, apartado 23, y Comisión/ Austria, C-614/10, EU:C:2012:631, apartado 37, tal como por otra parte se señala en el sexagésimo segundo considerando de la Directiva 95/46. 
De este modo, a juicio del TJUE, el artículo 28, apartado 1, párrafo segundo, de la Directiva 95/46, relativo a la independencia de la que venimos hablando, debe interpretarse en el sentido de que las autoridades de control competentes para vigilar el tratamiento de datos personales han de disfrutar de la independencia que les permita ejercer sus funciones sin influencia externa. Esta independencia excluye "toda orden o influencia externa con independencia de la forma que revista, directa o indirecta, que pudiera orientar sus decisiones y, en consecuencia, poner en peligro el cumplimiento de la tarea que corresponde a dichas autoridades de establecer un justo equilibrio entre la protección del derecho a la intimidad y la libre circulación de datos personales"63. De forma que la independencia funcional de las autoridades de control, en el sentido de que no estén sujetas a instrucción alguna en el ejercicio de sus funciones, es un requisito necesario para que dichas autoridades puedan ajustarse al criterio de independencia en el sentido del artículo 28, apartado 1, párrafo segundo, de la Directiva 95/46. No obstante, en contra de lo que afirma Hungría, tal independencia funcional no basta por sí sola para preservar a dichas autoridades de control de toda influencia externa. En este sentido, el TJUE ha declarado que la mera posibilidad de que las autoridades de tutela del Estado puedan ejercer influencia política sobre las decisiones de las autoridades de control es suficiente para obstaculizar el ejercicio independiente de las funciones de éstas. En efecto, por un lado, podría darse en tal caso una "obediencia anticipada" de las autoridades de control a la vista de la práctica decisoria de la autoridad de tutela. Por otro, habida cuenta del papel de guardianas del derecho a la intimidad que asumen las autoridades de control, el artículo 28, apartado 1, párrafo segundo, de la Directiva 95/46 exige que sus decisiones y, por tanto, ellas mismas, estén por encima de toda sospecha de parcialidad ${ }^{64}$.

Así pues, a juicio del TJUE, si cada Estado miembro tuviera la posibilidad de poner fin al mandato de una autoridad de control antes de que llegue al término previsto inicialmente, sin respetar las normas y las garantías establecidas por la legislación aplicable, la amenaza de tal terminación anticipada que en tal caso planearía sobre esa autoridad durante todo su mandato podría generar una forma de obediencia de ésta al poder político incompatible con dicha exigencia de independencia.

Igual sucede cuando la finalización del mandato antes de tiempo se deba a una reestructuración o a un cambio de modelo, los cuales deben organizarse de modo que respeten las exigencias de independencia impuestas por la legislación aplicable.

63 Véanse, en este sentido, las sentencias Comisión/Alemania, EU:C:2010:125, apartado 30, y Comisión/Austria, EU:C:2012:631, apartados 41 y 43.

64 Sentencias Comisión/Alemania, EU:C:2010:125, apartado 36, y Comisión/Austria, EU:C:2012:631, apartado 52. 
Por tanto, según considera el Tribunal de Justicia, debe interpretarse necesariamente que la exigencia de independencia contenida en el artículo 28, apartado 1, párrafo segundo, de la Directiva 95/46 incluye la obligación de respetar la duración del mandato de las autoridades de control hasta su expiración y de poner fin antes de tiempo al mismo únicamente cuando se observen las normas y las garantías de la legislación aplicable.

Ciertamente, los Estados miembros son libres de adoptar y modificar el modelo institucional que consideren más adecuado para sus autoridades de control, sobre la base de la autonomía institucional que se reconoce a los Estados miembros. Ahora bien, esa autonomía también conlleva que no se limite la independencia de la autoridad de control exigida por el artículo 28, apartado 1, párrafo segundo, de la Directiva 95/46, la cual implica la obligación de respetar la duración del mandato de tal autoridad.

A juicio del Tribunal, aunque el Supervisor y la Autoridad presenten diferencias sustanciales en lo que respecta a su organización y estructura, ambas entidades tienen encomendadas funciones fundamentalmente idénticas, por tanto, el mero cambio de modelo institucional no justifica objetivamente que pueda ponerse fin de manera anticipada al mandato de la persona que desempeñaba el cargo de Supervisor sin que se establezcan medidas transitorias en la legislación de Hungría que permitan garantizar que se respeta la duración de su mandato.

Por todo ello, el TJUE considera que debe declararse que Hungría ha incumplido las obligaciones que le incumben en virtud del artículo 28, apartado 1, párrafo segundo, de la Directiva 95/46 al poner fin antes de tiempo al mandato de la autoridad de control de la protección de datos personales.

Esta doctrina del TJUE se mantiene en materia de protección de datos en la que se garantizan directamente el ejercicio de los derechos fundamentales de los ciudadanos. Téngase en cuenta que se trata de un ámbito en el que, por muchas razones, debe extremarse la independencia entre el poder político y las autoridades reguladoras según la Directiva 95/46. Sin embargo, nos planteamos ahora si esta misma doctrina puede, incluso quiere, exportar al ámbito de las comunicaciones electrónicas en el que hay otros bienes jurídicos tutelados de naturaleza jurídica diferente y que apuntan al funcionamiento del mercado y la garantía de una competencia libre y efectiva.

\section{En materia de telecomunicaciones.}

\subsection{El caso de España.}

Una vez analizada la eficacia de la independencia y neutralidad política de la normativa europea de protección de datos ante el cese de miembros de ANRs antes 
del plazo legalmente previsto y sin contemplarse como una de las causas para ello, examinamos el alcance que adquiere en materia de telecomunicaciones. En particular, en España, se produjo el cese de miembros de la ANRs de telecomunicaciones, la extinta Comisión del Mercado de Telecomunicaciones (CMT), antes de plazo previsto y sin concurrir causa alguna según la norma aplicable, por la creación de la GNMC. En este contexto, los miembros cesados interpusieron recurso contencioso-administrativo ante el TS contra los Reales Decretos 795/13 y 800/13, de 11 de octubre, en los que se acordaba el cese de los mismos. Esta cuestión, sin duda, controvertida ha dado lugar al Auto, el 3 de julio de 2015 (recurso número 506/2013), del TS, que plantea diversas cuestiones prejudiciales al TJUE en la materia objeto de nuestro estudio, y a las conclusiones del Abogado General de 30 de junio de 2016. También se ha pronunciado el TJUE en la sentencia de 19 de octubre de 2016 (asunto C-424/153 y el TS en la sentencia de 3 de noviembre de 2016 (recurso T7/2016) ${ }^{65}$.

Como resulta obvio, el pronunciamiento del TJUE en el caso de Hungría tiene gran relevancia para la resolución del caso de España, pues aunque afectan a ámbitos diferentes (protección de datos de carácter personal y comunicaciones electrónicas) es inevitable equipararlos. Recordemos que la GNMG es el organismo resultante de la fusión de los reguladores sectoriales, entre otros, de la energía (CNE) y las telecomunicaciones (CMT), así como de la autoridad de la competencia $(\mathrm{GNC})$.

\subsection{La postura del TS español.}

Inicialmente, la Sala Tercera del TS dictó un Auto, el 3 de julio de 2015 (recurso número 506/2013), que resulta del recurso contencioso-administrativo citado -interpuesto por el expresidente y un exconsejero de la extinta CMT ante el TS contra los Reales Decretos 795/13 y 800/13, de 11 de octubre, en los que se acordaba el cese de los mismos-. En el escrito de demanda, los recurrentes solicitaron al TS que formulara al TJUE cuestión prejudicial ${ }^{66}$ con el fin de que determinara si los Reales

65 Recordamos que en el momento de realizar este trabajo ni el TJUE ni el TS habían dicatos sus sentencias.j126.

${ }_{66}$ De forma exacta el Auto recoge las dos cuestiones que sugieren los recurrentes para plantear cuestión prejudicial al TJUE: "Primero:- Si el artículo 3.3 Bis de la Directiva 2009/140/CE del Parlamento Europeo y del Consejo, de 25 de noviembre, por la que se modifican la Directiva 2002/21/CE; relativa a un marco regulador común de las redes y los servicios de comunicaciones electrónicas, la Directiva 2002/19/ $\mathrm{CE}$, relativa al acceso a las redes de comunicaciones electrónicas y recursos asociados, y a su interconexión, y la Directiva 2002/20/CE, relativa a la autorización de redes y servicios de comunicaciones electrónicas, es directamente aplicable en los estados, en caso de haberse derogado las garantías legales de transposición, como ha sucedido al derogarse los artículos 13 y 16 de la Ley 2/2011, de 4 de marzo, de Economía Sostenible (BOE de 5 de marzo de 2011), por la letra h) de la disposición derogatoria de la Ley 3/2013, de 4 de junio, de creación de la Comisión Nacional de los Mercados y la Competencia (BOE 5 junio).

Segundo.- Si el Real Decreto 795/2013, de 11 de octubre, por el que se dispone el cese de Don Bernardo Lorenzo Almendros como Presidente de la Comisión del Mercado de las Telecomunicaciones y 
Decretos impugnados resultan ilegales por infringir el art. 3.3 bis de la Directiva Marco $^{67}$. El Abogado del Estado, por escrito de 13 de mayo de 2015, se opuso al planteamiento de la cuestión prejudicial.

Recordemos que la CMT se creó por el Real Decreto-ley 6/1996, de 7 de junio, de Liberalización de las Telecomunicaciones, como "órgano independiente encargado de velar por la aplicación de tales principios y de arbitrar los conflictos entre los operadores del sector". La citada norma de creación fue derogada y sustituida por la Ley 12/1997, de 24 de abril, de Liberalización de las Telecomunicaciones, también derogada y reemplazada por la Ley 32/2003, de 3 de noviembre, General de Telecomunicaciones, por la que se transponen diversas Directivas europeas (del conocido paquete "telecom" de 2002).

Por su parte, la Ley 2/2011, de 4 de marzo, de Economía Sostenible, justificó en su momento la reforma de los organismos reguladores y de supervisión, reforzando su independencia frente al Gobierno y a las empresas reguladas, y sometiéndolos al control parlamentario y judicial. Con este fin, el artículo 13 contemplaba la forma

el Real Decreto 800/2013, de 11 de octubre, por el que se dispone el cese de Don Xabier Ormaetxea Garai como Consejero de la Comisión del Mercado de las Telecomunicaciones son ilegales por haber infringido el artículo 3.3 Bis de la Directiva Marco anteriormente citada (marco regulador común de las redes y los servicios de comunicaciones electrónicas, Directiva marco)."

${ }^{67}$ El artículo 3.3. bis de la Directiva 2009/140/CE, del Parlamento Europeo y del Consejo, de 25 de noviembre, relativa a un marco regulador común de las redes y los servicios de comunicaciones electrónicas, establece que: "Los Estados miembros velarán por que el responsable de la autoridad nacional de reglamentación o, cuando proceda, los miembros del órgano colegiado que desempeñen dicha función en el seno de la autoridad nacional de reglamentación a la que se refiere el párrafo primero o sus sustitutos solo puedan ser cesados en caso de que dejen de cumplir las condiciones requeridas para el ejercicio de sus funciones, que hayan sido establecidas de antemano en el Derecho nacional. La decisión de cesar al responsable de la autoridad nacional de reglamentación de que se trate o, si procede, a los miembros del órgano colegiado que desempeñen dicha función, se hará pública en el momento del cese. El responsable de la autoridad nacional de reglamentación que haya sido cesado o, si procede, los miembros del órgano colegiado que desempeñen dicha función recibirán una exposición de los motivos de la decisión y tendrá derecho a solicitar que sea publicada, cuando no lo haya sido, en cuyo caso deberá atenderse su solicitud." 
del nombramiento del Presidente y los Consejeros de la CMT, y la duración del mandato, así como su renovación ${ }^{68}$, hasta su derogación por la Ley 3/2013 de creación de la CNMC $^{69}$. Seguidamente, unos días después, el 10 de marzo de 2011, se publicaron en el BOE los nombramientos del Presidente y del Consejero de la CMT.

68 La Ley 2/2011, de 4 de marzo, de Economía Sostenible (BOE de 5 de marzo de 2011) en el preámbulo (Aparatado III) exponía que: "El Capítulo II aborda la reforma de los organismos reguladores introduciendo por primera vez en nuestro ordenamiento un marco horizontal, común a todos ellos, que asume sus características de independencia, frente al Gobierno y frente al sector correspondiente, y su actuación de acuerdo con principios de eficiencia y transparencia. Así, se reduce el número de miembros de los Consejos con el fin de mejorar al gobernanza de las instituciones, y se establecen nuevos mecanismos de rendición de cuentas, a través de la comparecencia del Ministerio proponente y de los candidatos a Presidente y a Consejeros del organismo regulador ante el Parlamento y de la elaboración de un informe económico sectorial y un plan de actuación del organismo. La propia Ley determina su ámbito de aplicación a la Comisión Nacional de Energía, la Comisión del Mercado de las Telecomunicaciones y la Comisión Nacional del Sector Postal, declarando aplicables buena parte de sus preceptos a la Comisión Nacional de la Competencia. Quedan por ahora fuera de este marco común los organismos vinculados al ámbito financiero, que deberán adecuarse a las reglas resultantes del proceso de discusión sobre su régimen que actualmente se desarrolla en el ámbito internacional y europeo". Por su parte, el artículo 13 afirmaba que: "1. El Presidente y los Consejeros serán nombrados por el Gobierno, mediante Real Decreto, a propuesta del titular del Ministerio competente, entre personas de reconocido prestigio y competencia profesional, previa comparecencia del Ministro, y de las personas propuestas como Presidente y Consejeros ante la Comisión correspondiente del Congreso de los Diputados, que versará sobre la capacidad de los candidatos. La comparecencia del Presidente, además, se extenderá a su proyecto de actuación sobre el organismo y sobre el sector regulado. 2. El mandato del Presidente y los Consejeros será de seis años sin posibilidades de reelección como miembro del Consejo, La renovación de los Consejeros se hará parcialmente para fomentar la estabilidad y continuidad del Consejo". El artículo 16 establecía una lista tasada de posibles causas para el cese del Presidente y Consejeros de los organismos reguladores: a) Por renuncia; b) Por expiración del término de su mandato; c) Por incompatibilidad sobrevenida; d) Por haber sido condenado pro delito doloso; e) Por incapacidad permanente; f) Mediante separación acordada por el Gobierno por incumplimiento grave de los deberes de su cargo o el incumplimiento de las obligaciones sobre incompatibilidades, conflictos de interés, y del deber de reserva. La separación será acordada por el Gobierno, con independencia del régimen sancionador que en su caso pudiera corresponder, previa instrucción de expediente por el titular del Ministerio competente. Por último, la Disposición Adicional Novena, relativa a la adaptación de la composición del número de miembros del Consejo de los organismos reguladores y de la Comisión Nacional de la Competencia, estableció que, en el plazo de 2 meses desde la entrada en vigor de dicha Ley, el Gobierno acordaría, mediante Real Decreto, el cese de aquellos miembros de los Consejos de los Organismos, cuyo mandato hubiera expirado en el momento de entrada en vigor del citado Real Decreto, señalando asimismo que la designación de nuevos Presidentes de los organismos tendrá lugar a partir del momento en que expire el mandato de los actuales Presidente, y la de los nuevos Consejeros a partir del momento en que el número de Consejeros cuyo mandato vaya expirando sea inferior a seis. La citada Ley establecía la supresión del cargo de Vicepresidente de los Consejos de los organismos reguladores, y en su Disposición adicional novena, en su punto 4 señala que: "A la entrada en vigor de esta Ley, los vicepresidentes de los Organismos continuaran en su cargo hasta la expiración de su mandato, momento en el cual el cargo de vicepresidente en cada Organismo quedará suprimido".

69 A continuación, sólo unos días después, el 10 de marzo de 2011, se publicaron en el BOE los nombramientos del Presidente (D. Bernardo Lorenzo Almendros), y del Consejero (D. Xabier Ormaetxea Garai), de la CMT. 
Dos años después de los nombramientos citados, se aprueba la Ley 3/2013, de 4 de junio, de creación de la Comisión Nacional de los Mercados y la Competencia (CNMC en adelante) y se deroga el art. 13 de la Ley 2/2011 de Economía Sostenible ${ }^{70}$.

$70 \quad$ La Ley 3/2013, de 4 de julio, de creación de la GNMC en el preámbulo prevé que: "Transcurrido cierto tiempo desde la implantación de este sistema, que ha reportado indudables ventajas para el proceso de liberalización y transición a la competencia de los sectores regulados, es necesario revisarlo. Desde 2011 ha crecido notablemente el número de estos organismos. Hasta entonces eran cinco: Comisión Nacional de Energía, Comisión del Mercado de las Telecomunicaciones, Comisión Nacional de la Competencia, Comité de Regulación Ferroviaria y Comisión Nacional del Sector Postal. La Ley 2/2011, de 4 de marzo, de Economía Sostenible, previó la constitución de un sexto, el organismo regulador del sector del transporte. Más tarde, se aprobó la creación de la Comisión Nacional del Juego y la Comisión de Regulación Económica Aeroportuaria. A ellos hay que unir el Consejo Estatal de Medios Audiovisuales, regulado en la Ley 7/2010, de 31 de marzo, General de la Comunicación Audiovisual. A la hora de plantear la revisión del sistema, el primer elemento que ha de tomarse en consideración es algo que debe caracterizar, no ya a cualquier mercado, sino a todos los sectores de la actividad económica: la seguridad jurídica y la confianza institucional. Estas se consiguen con unas normas claras, una arquitectura institucional seria y unos criterios de actuación conocidos y predecibles por todos los agentes económicos. Cuanto mayor sea la proliferación de organismos con facultades de supervisión sobre la misma actividad, más intenso será el riesgo de encontrar duplicidades innecesarias en el control de cada operador y decisiones contradictorias en la misma materia. En segundo lugar, de modo especialmente importante en el entorno de austeridad en el que se encuentra la Administración Pública, se deben aprovechar las economías de escala derivadas de la existencia de funciones de supervisión idénticas o semejantes, metodologías y procedimientos de actuación similares y, sobre todo, conocimientos y experiencia cuya utilización en común resulta obligada. En tercer lugar, las instituciones han de adaptarse a la transformación que tiene lugar en los sectores administrados. Debe darse una respuesta institucional al progreso tecnológico, de modo que se evite el mantenimiento de autoridades estancas que regulan ciertos aspectos de sectores que, por haber sido objeto de profundos cambios tecnológicos o económicos, deberían regularse o supervisarse adoptando una visión integrada. En los últimos años, se detecta una clara tendencia a nivel internacional a fusionar autoridades relacionadas con un único sector o con sectores que presentan una estrecha relación, pasando del modelo uni-sectorial a un modelo de convergencia orgánica, material o funcional en actividades similares o a un modelo multisectorial para sectores con industrias de red. Las ventajas que han motivado la adopción de estos modelos son las de optimizar las economías de escala y garantizar el enfoque consistente de la regulación en todas las industrias de red. Además, se ha argumentado que el riesgo de captura del regulador, tanto por el sector privado como por el gobierno, es menor en el caso de las autoridades multisectoriales, al reducirse la importancia relativa de un determinado sector o de un determinado ministerio para la autoridad. Por último, en algunos casos, como el de los Países Bajos, se han integrado las autoridades reguladoras de ciertos sectores en la autoridad de competencia. Con ello se consigue una mayor eficacia en la supervisión de la competencia en los mercados, al poder contar de forma inmediata con el conocimiento de los reguladores sectoriales, que ejercen un control continuo sobre sus respectivos sectores a través de instrumentos de procesamiento de datos más potentes. La situación actual en España, en la que se ha aprobado la creación de ocho organismos supervisores vinculados a los mercados de productos y de servicios y se ha previsto la creación de otro más, debe evolucionar hacia los modelos que se están implantando en los países de nuestro entorno. La filosofía que subyace en la existencia de todos estos organismos es fundamentalmente velar por unos mercados competitivos y unos servicios de calidad, en beneficio de los ciudadanos. La presencia de todas estas entidades de forma separada, con sus respectivos órganos de gobierno y medios materiales, exige una reforma de calado teniendo en cuenta la existencia de funciones, procedimientos, metodologías y conocimientos que, por su identidad o semejanza, bien podrían ejercerse o aplicarse por una sola institución. La normativa europea 
Y, a continuación, se aprueba el Estatuto Orgánico de la CNMC mediante Real Decreto 657/2013, de 30 de agosto $^{71}$ y el 10 de septiembre de 2013 se publicaron los Reales Decretos de nombramiento de Presidente y Consejeros de la CNMC ${ }^{72}$.

Los recurrentes, llegados a este punto ${ }^{73}$, impugnan ante el TS los Reales Decretos que acuerdan sus ceses como Consejero y Presidente, respectivamente, de la CMT y entienden que la aplicación retroactiva de los ceses supone una flagrante

prevé la existencia de autoridades reguladoras nacionales independientes, dotándolas de misiones, objetivos y competencias concretas. No obstante, las competencias de las comisiones en España son más amplias que las requeridas por la normativa europea, en lo referente a la política sectorial, la concesión y revocación de títulos habilitantes para el ejercicio de determinadas actividades, el asesoramiento al Gobierno y el estudio e investigación de los sectores. Por ello, el objeto de esta Ley es la creación de la Comisión Nacional de los Mercados y la Competencia, que agrupará las funciones relativas al correcto funcionamiento de los mercados y sectores supervisados por la Comisión Nacional de Energía, la Comisión del Mercado de las Telecomunicaciones, la Comisión Nacional de la Competencia, el Comité de Regulación Ferroviaria, la Comisión Nacional del Sector Postal, la Comisión de Regulación Económica Aeroportuaria y el Consejo Estatal de Medios Audiovisuales.”. Además, el “Capítulo I, 'Naturaleza y régimen jurídico', procede a la creación de la Comisión Nacional de los Mercados y la Competencia, cuyo objeto es garantizar, preservar y promover el correcto funcionamiento del mercado, así como la transparencia y la existencia de una competencia efectiva en todos los mercados y sectores productivos en beneficio de los consumidores y usuarios. La Comisión se configura como un organismo público de los previstos en la Disposición adicional décima de la Ley 6/1997, de 14 de abril, de Organización y Funcionamiento de la Administración General del Estado. La Comisión está dotada de personalidad jurídica propia y plena capacidad pública y privada y actuará con pleno sometimiento a la ley, con autonomía orgánica y funcional y con plena independencia del Gobierno, de las Administraciones Públicas y de cualquier interés empresarial y comercial. Sin perjuicio de su independencia, la Comisión velará por la aplicación uniforme de la normativa sectorial y general de competencia en el territorio nacional mediante la cooperación con la Administración General del Estado, con las Comunidades Autónomas, con los órganos jurisdiccionales, con las instituciones y organismos de la Unión Europea, en especial con la Comisión Europea, y con las autoridades competentes y organismos de otros Estados miembros en el desarrollo de su actividad." Por su parte, el artículo 23.1 prevé las causas de cese de los Consejeros, que son idénticas a la de la anterior Ley: a) Por renuncia aceptada por el Gobierno; b) Por expiración del término de su mandato; c) Por incompatibilidad sobrevenida; d) Por haber sido condenado por delito doloso; e) Por incapacidad permanente; f) Mediante separación acordada por el Gobierno por incumplimiento grave de los deberes de su cargo o el incumplimiento de las obligaciones sobre incompatibilidades, conflictos de interés y del deber de reserva.

71 En el BOE de 31 de agosto de 2013 se publicó el Real Decreto 657/2013, de 30 de agosto.

72 En el BOE de 15 de octubre de 2013 se publicaron los Reales Decretos 795/2013 y 800/2013, de 11 de octubre, por los que se disponía el cese del Presidente y del Consejero del Mercado de las Telecomunicaciones, con efectos retroactivos de 7 de octubre de 2013.

73 Téngase en cuenta que antes de interponer recurso contencioso administrativo ante el TS, el 29 de octubre de 2013, mediante escrito presentado al Ministerio de Industria, Energía y Turismo, D.Xabier Ormaetxea Garai, solicitó la nulidad del Real Decreto 800/2013 por el que se le cesaba como Consejero de la CMT. Solicitó asimismo que se le comunicasen expresamente las causas legales que motivaban su cese, y que se publicase éste en la forma legal oportuna, con indicación de las causas del mismo, y efectos legales desde su publicación. El 4 de noviembre de 2013, dicho Consejero remitió un escrito a la Comisión Europea solicitando su amparo, ante la vulneración de derechos derivada de su cese que contraviene la Directiva Marco Europea en su art. 3.3.bis. Con fecha 8 de enero de 2014 la Comisión Europea informó por carta 
contravención del principio de irretroactividad conforme a lo consagrado en el ordenamiento jurídico español, y los principios generales del derecho. A lo anterior se suma, a juicio de los recurrentes, que los citados Reales Decretos no motivan los ceses acordados antes de expirar el término de su mandato inicialmente previsto de seis años, pues en ellos no se expone ningún tipo de motivación a la decisión ${ }^{74}$, por ello son contrarios al art. 3.3 bis de la Directiva 2009/140/CE del Parlamento Europeo y del Consejo, de 25 de noviembre, por la que se modifica la Directiva 2002/21/CE, relativa a un marco regulador común de las redes y los servicios de comunicaciones electrónicas y recursos asociados.

El TS tras hacer un repaso de la normativa española y europea aplicable al supuesto concreto, trae a colación pronunciamientos del TJUE en los que interpreta la Directiva Marco en materia de comunicaciones electrónicas según los cuales, de conformidad con el principio de separación de las funciones de regulación y de explotación, los Estados miembros deben garantizar la independencia de la autoridad o autoridades nacionales de reglamentación con el fin de asegurar la imparcialidad de sus decisiones.

En la sentencia de 6 de marzo de 2008 (asunto C-82/2007), el TJUE interpreta el marco regulador aplicable a las telecomunicaciones de $2002^{75}$ y afirma que: "éste es el contexto en el que debe interpretarse el undécimo considerando de la Directiva marco, según el cual, de conformidad con el principio de separación de las funciones de regulación y de explotación, los Estados miembros deben garantizar la independencia de la autoridad o autoridades nacionales de reglamentación (...) con el fin de asegurar la imparcialidad de sus decisiones". Así pues, el Tribunal de Justicia, afirma que el undécimo considerando de la Directiva marco "obliga a los Estados miembros a garantizar la independencia de la autoridad o autoridades de reglamentación, como por el artículo 3, apartado 4, de la misma Directiva, que dispone que los Es-

al Sr. Ormaetxea que su solicitud de amparo, o queja, había sido registrada con el número de referencia CHAP (20014)00043.

74 Además, de forma previa a la aprobación de los Reales Decretos no se instruyó ningún expediente ni se produjo siquiera la comunicación de los motivos a los demandantes, omisión que contravino lo previsto en el párrafo $2^{\circ}$ del art. 3.3 in fine de la Directiva 2009/19/CE, relativa al acceso a las redes de comunicaciones electrónicas y recursos asociados, y a su interconexión, y la Directiva 2002/20/CE, relativa a la autorización de redes y servicios de comunicaciones electrónicas

75 Este conjunto normativo se conoce como el segundo paquete telecom de 2002 y se integra por la Directiva 2002/21/CE, del Parlamento Europeo y del Consejo, de 7 de marzo, relativa a un marco regulador común de las redes y los servicios de comunicaciones electrónicas (Directiva marco) y las Directivas 2002/20/CE del Parlamento Europeo y del Consejo, de 7 de marzo de 2002, relativa a la autorización de redes y servicios de comunicaciones electrónicas (Directiva autorización), 2002/22/CE del Parlamento Europeo y del Consejo de 7 de marzo de 2002, relativa al servicio universal y los derechos de los usuarios en relación con las redes y los servicios de comunicaciones electrónicas (Directiva servicio universal), y Directiva 2002/19/CE del Parlamento Europeo y del Consejo, de 7 de marzo de 2002, relativa al acceso a las redes de comunicaciones electrónicas y recursos asociados y a su interconexión (Directiva acceso). 
tados miembros deberán publicar las misiones que incumban a estas autoridades de reglamentación, en particular cuando dichas misiones se asignen a más de un organismo". De igual modo, en la sentencia del TJUE de 6 de octubre de 2010 (asunto C-398/2008), el Tribunal de Justicia entiende que del undécimo considerando de la Directiva Marco se desprende que, de conformidad con el principio de separación de las funciones de regulación y de explotación, los Estados miembros deben garantizar la independencia de la autoridad o autoridades nacionales de reglamentación con el fin de asegurar la imparcialidad de sus decisiones, y que éstas deben disponer de todos los recursos necesarios en cuanto a personal, competencia y medios financieros para el cumplimiento de sus misiones.

Tampoco es ajeno el TS al caso de Hungría, al que hace referencia y que ya conocemos ${ }^{76}$.

Así pues, según el TS, los motivos que justifican que se planteen las cuestiones prejudiciales al TJUE giran, de un lado, en torno a las condiciones de "independencia" de las autoridades nacionales de regulación en materia de redes y servicios de comunicaciones electrónicas. En particular, se pone en tela de juicio si dichas condiciones han de ser análogas a las requeridas para las autoridades nacionales de control de protección de datos personales según el artículo 28 de la Directiva 95/46/CE y si el cese anticipado de sus Consejeros, en los términos en que ha tenido lugar, pudiera afectar a aquella independencia. El TS también expresa sus dudas sobre la compati-

76 En la sentencia de 8 de abril de 2014 (asunto C-288/2012, Comisión vs. Hungría), el Tribunal de Justicia de la Unión Europea se pronuncia sobre la exigencia de "independencia en el ejercicio de las funciones" a la que se refiere el artículo 28, apartado 1, párrafo segundo de la Directiva 95/46 que ha de garantizarse a las autoridades de control: "50 para apreciar el fundamento del presente recurso es necesario analizar sí, como sostiene la Comisión, la exigencia, contemplada en el artículo 28, apartado 1, párrafo segundo, de la Directiva 95/46, según la cual debe garantizarse que cada autoridad de control ejerza con total independencia las funciones que le son atribuidas, implica que el Estado miembro de que se trate está obligado a respetar la duración del mandato de tal autoridad hasta que llegue a su término inicialmente previsto". Y en sus apartados 54 y 55 afirma: " 54 . Pues bien, si cada Estado miembro tuviera la posibilidad de poner fin al mandato de una autoridad de control antes de que éste llegue al término inicialmente previsto sin respetar las normas y las garantías establecidas previamente en tal sentido por la legislación aplicable, la amenaza de tal terminación anticipada que en tal caso planearía sobre esa autoridad durante todo su mandato podría generar una forma de obediencia de ésta al poder político incompatible con dicha exigencia de independencia (véase, en este sentido, la sentencia Comisión /Austria, EU:C:2012:631, apartado 51). Esta conclusión es también cierta en el caso de que la finalización del mandato antes de tiempo obedezca a una reestructuración o a un cambio de modelo, los cuales deben organizarse de modo que respeten las exigencias de independencia impuestas por la legislación aplicable. 55 Además, en tal situación, no cabría considerar que la autoridad de control pueda actuar, en cualquier circunstancia, por encima de toda sospecha de parcialidad. Así pues, debe interpretarse necesariamente que la exigencia de independencia contenida en el artículo 28, apartado 1, párrafo segundo, de la Directiva 95/46 incluye la obligación de respetar la duración del mandato de las autoridades de control hasta su expiración y de poner fin antes de tiempo al mismo únicamente cuando se observen las normas y las garantías de la legislación aplicable”. 
bilidad con el derecho de la Unión Europea de la existencia de un solo organismo de supervisión y regulación, la CNMC, que agrupa las funciones relativas al correcto funcionamiento de los mercados y sectores supervisados con anterioridad por diversos organismos. A juicio del TS, lo cuestionable es si la fusión en un solo órgano de regulación y supervisión de los anteriores órganos reguladores u supervisores -existentes hasta entonces en los ámbitos de la energía, telecomunicaciones, defensa de la competencia y otros- resulta compatible, en concreto, con la configuración de los órganos nacionales de regulación en materia de redes y servicios de comunicaciones electrónicas que se desprende de la Directiva 2002/21/CE. En consecuencia, el TS en el Auto manifiesta sus titubeos en cuanto a la existencia de razones suficientes para considerar si, con ocasión de una reforma legal que reordena la organización general de los órganos reguladores, es posible no respetar la totalidad del mandato de los Consejeros y del Presidente de la ya no existente CMT, inicialmente previsto. Recuérdese que antes de que transcurrieran seis años desde su nombramiento se puso fin, de forma anticipada, a dicho mandato, sin que los titulares del órgano hubieran incurrido en ninguna de las causas legales de cese, siendo debido éste, como única razón, a la aprobación de la Ley 3/2013. Además, el TS trae a colación el concepto de "independencia" ya interpretado por el TJUE en el sentido que se extiende al respeto del mandato legal. En el mismo sentido, el artículo 3.3 bis de la Directiva 2009/140/ CE contempla la obligación de los Estados Miembros de velar por que el responsable de la autoridad nacional de reglamentación o los miembros del órgano colegiado que desempeñen sus funciones en el seno de la autoridad nacional de reglamentación sólo sean cesados cuando dejen de cumplir las condiciones requeridas para el ejercicio de sus funciones.

Con todo lo anterior, según razona el TS en el Auto, durante el período de mandato preestablecido (de seis años, según la Ley 2/2011) los Consejeros y el Presidente de los organismos reguladores no podían cesar si no era por la concurrencia de alguna de las causas taxativamente enumeradas en el artículo 16 de la ley vigente en el momento del nombramiento. Además, la reforma legal operada por la Ley 3/2013 reordena las autoridades reguladoras nacionales y subraya su naturaleza de organismos "independientes". El preámbulo afirma mantener y reforzar esta independencia así como la suficiencia de recursos, y como garantía y manifestación de dicha independencia establece en su artículo 23.1 las mismas causas taxativas de cese que las contempladas en la anterior Ley 2/2011. No obstante, a juicio del TS, "sin concurrir ninguna de las causas expuestas en el artículo 16 de la Ley 2/2011 y con ocasión -y como efecto- de la reforma legal se produce el cese anticipado de los Consejeros y del Presidente inicialmente designados, sin haber expirado todavía su mandato y, reiteramos, sin incurrir en alguna de las causas legales hasta entonces previstas. El cese de los referidos Presidente y Consejero se vincula, pues, como también ha quedado 
expuesto, a la 'necesidad de reforma de los organismos reguladores' emprendida por la Ley 3/2013 por las razones que se exponen en su preámbulo. La medida de cese podría parecer, de nuevo y en una primera aproximación, amparada en la libertad de los Estados Miembros de decidir el modelo de sus autoridades nacionales de regulación. Se trataría de una reforma realizada por una norma legal que varía el modelo anterior y crea una nueva organización a fin de conseguir una mayor eficiencia y coordinación de los organismos reguladores y supervisores."

Siguiendo la argumentación que realiza el TS en el Auto, incluso admitiendo la legítima posibilidad legal de abordar las reformas necesarias de los organismos reguladores, "lo que se aprecia es que tal reforma ha implicado por sí misma, y sin ninguna otra razón adicional, la terminación anticipada del mandato de los anteriores designados. No ha concurrido ninguna de las causas legales previstas y esta circunstancia, unida a la inexistencia de disposiciones transitorias dirigidas a permitir la conclusión del mandato por los consejeros designados al amparo de la anterior Ley, podría considerarse contraria a las exigencias de independencia. Más en concreto, podría afectar a la independencia de los miembros del órgano regulador frente a posibles injerencias externas y, en particular, a la obligación de los Estados miembros de velar por el respeto al mandato integro de los nombrados conforme al artículo 3.3 bis de la Directiva Marco. Y es que, una vez designados los integrantes de los órganos reguladores durante el tiempo de seis años, podría sostenerse que cualquier reforma legal que incida en el modelo o en la organización de los órganos de regulación debería partir del respeto del precedente mandato reconocido. Se trataría de una cautela que permitiría la observancia y el respeto en su plenitud de los períodos temporales previamente establecidos."

Por ello, aun en el caso de que se aceptase por válido el nuevo diseño institucional, a juicio del Tribunal, seguiría habiendo dudas sobre si la creación de la CNMC a través de la Ley 3/2013, con la consecuencia del cese inmediato de los anteriores miembros designados, y sin medidas transitorias específicas que les permitieran agotar el mandato inicial, pudiera ser contraria o afectar de alguna manera a la independencia de los organismos reguladores y a la obligación que incumbe a los Estados Miembros de garantizar el mandato con arreglo al artículo 3.3 bis de la Directiva Marco.

En definitiva, según el TS, la reforma legislativa nacional y sus consecuencias, sobre todo los Reales Decretos que disponen el cese de los recurrentes sin otra cobertura que la reforma legal y que son objeto del recurso contencioso administrativo, obligan al Tribunal español a plantear cuál ha de ser la interpretación válida de la Directiva Marco. También, si el concepto de independencia de la autoridad de regulación ha de ser interpretada a la luz de las consideraciones que ya ha efectuado el 
TJUE en la sentencia del caso de Hungría, en relación a un organismo supervisor de la protección de datos ${ }^{77}$.

2.3. La interpretación europea del Abogado General: el cese de miembros de una ANR antes de la finalización del mandato menoscaba su independencia.

El Abogado General (YVES BOT) presentó sus Conclusiones, de 30 de junio de 2016, y aglutina en dos las cuestiones prejudiciales que plantea el TS al TJUE para su análisis: Primera, si la Directiva marco debe interpretarse en el sentido de que la fusión de una ANR, en el marco de una reforma institucional, con otras autoridades reguladoras incumple los requisitos previstos en las disposiciones de esta Directiva, relativos en particular, a la independencia, la capacidad y la competencia técnica de esta ANR; Segunda, si el artículo 3, apartado 3 bis, de la Directiva marco debe interpretarse en el sentido de que el cese del presidente y de un consejero de una ANR antes de que finalice su mandato como consecuencia de una reforma institucional al efecto de fusionar esta ANR con otras autoridades reguladoras menoscaba la garantía de independencia de esa ANR.

La primera cuestión prejudicial lleva a examinar, -a la luz de la autonomía institucional de la que disfrutan los Estados miembros en la materia-, el margen de maniobra de que disponen los Estados miembros para organizar y reestructurar sus ANRs. A juicio de Abogado General, la Directiva marco no impone ningún requisi-

77 El TS plantea al TJUE las siguientes cuestiones prejudiciales, a la luz de lo dispuesto en el artículo 267 del Tratado de Funcionamiento de la Unión Europea: a) La interpretación de la Directiva 2002/21/ CE, del Parlamento Europeo y del Consejo, de 7 de marzo de 2002, relativa a un marco regulador común de las redes y los servicios de comunicaciones electrónicas, ¿permite considerar compatible con ella, desde la perspectiva de salvaguarda efectiva de los intereses generales que competen al órgano nacional de regulación en esta materia, la creación por el legislador nacional de un órgano de regulación y supervisión que responda a un modelo institucional de carácter no especializado, que fusiona en un solo organismo los órganos de control en el ámbito de la energía, las telecomunicaciones y la competencia, entre otros, existentes hasta entonces?; b) ¿Las condiciones de "independencia” de las autoridades nacionales de regulación en materia de redes y servicios de comunicaciones electrónicas, a las que se refiere el artículo 3, apartados 2 y 3 bis de la Directiva 2002/21/CE, modificada por la Directiva 2009/140/CE, han de ser análogas a las requeridas para las autoridades nacionales de control de protección de datos personales según el artículo 28 de la Directiva 95/46/CE?; c) ¿Sería aplicable la doctrina contenida en la sentencia del Tribunal de Justicia de la Unión Europea de 8 de abril de 2014 al supuesto en que los responsables de una autoridad nacional de reglamentación de las telecomunicaciones son cesados antes de la expiración de su mandato por exigencia de un nuevo marco legal que crea un órgano de supervisión en el que se agrupan diversas autoridades nacionales de reglamentación de sectores regulados? Dicho cese anticipado, por la mera entrada en vigor de una nueva ley nacional y no por la pérdida sobrevenida de las condiciones personales de sus titulares que fueron establecidas de antemano en el derecho nacional, ¿puede considerarse compatible con lo dispuesto en el artículo 3, apartado 3 bis, de la Directiva 2002/21/CE?. 
to en cuanto a la forma que ha de tener una $\mathrm{ANR}^{78}$. Así pues, el TJUE ha admitido que la Directiva 2002/22/CE ${ }^{79}$ no se opone, por sí misma, a que el legislador nacional intervenga en condición de ANR en el sentido de la Directiva marco, o a que un Estado miembro asigne a varios organismos las misiones derivadas de la aplicación del nuevo marco regulador, a condición de que, en el ejercicio de sus funciones, esos organismos cumplan los requisitos de competencia, independencia, imparcialidad y transparencia establecidos en estas Directivas y de que las decisiones que adopten en el ejercicio de sus funciones puedan ser objeto de un recurso efectivo ante un organismo independiente de las partes implicadas. Así pues, varias autoridades reglamentarias independientes, incluidas autoridades ministeriales, pueden compartir las funciones de asignación de los recursos de numeración nacionales y de gestión de los planes nacionales de numeración, delegadas a la ANR, siempre que el reparto de las misiones se haga público, sea fácilmente accesible y se notifique a la Comisión. De la jurisprudencia del TJUE se desprende que, en el marco de su autonomía institucional, los Estados miembros disponen de un amplio margen de maniobra en cuanto a la organización y a la estructuración de sus ANRs, cuyo límite está en el respeto a los requisitos y las garantías establecidos en la Directiva marco ${ }^{80}$.

Por tanto, a juicio del Abogado General, y conforme al art. 3.2 de la Directiva marco, la entidad nacional responsable de cumplir las funciones que ésta asigna a la ANR "debe ser jurídicamente distinta y funcionalmente independiente de todas las entidades suministradoras de redes, equipos o servicios de comunicaciones electrónicas, y, en su caso, el Estado miembro debe velar por la separación estructural efectiva entre la función de regulación, por un lado, y las actividades relacionadas con la propiedad o el control de empresas suministradoras de redes o servicios de comunicaciones electrónicas, por otro”. Además, para cumplir los requisitos establecidos en el citado precepto de la Directiva marco, esta entidad "debe poder ejercer

78 El Abogado General recuerda que el artículo 2, letra g), de la Directiva Marco se limita a definir la ANR como "organismo u organismos a los cuales ha encomendado un Estado miembro cualquiera de las misiones reguladoras asignadas en [dicha] Directiva y en las directivas específicas." Por otro lado, en virtud de reiterada jurisprudencia, si bien los Estados miembros gozan de autonomía institucional en esta materia respecto de la organización y estructuración de sus ANR, en el sentido de esta disposición, dicha autonomía sólo puede ejercerse, no obstante, respetando plenamente los objetivos y las obligaciones establecidos en la Directiva marco. Véase la sentencia de 17 de septiembre de 2015, KPN (C-85/14, EU:C:2015:610), apartado 53 y jurisprudencia citada.

79 Directiva del Parlamento Europeo y del Consejo, de 7 de marzo de 2002, relativa al servicio universal y los derechos de los usuarios en relación con las redes y los servicios de comunicaciones electrónicas (Directiva servicio universal) (DO 2002, L 108, p. 51), en su versión modificada por la Directiva 2009/136/ CE del Parlamento Europeo y del Consejo, de 25 de noviembre de 2009 (DO 2009, L 337, p. 11).

80 Véase la sentencia de 6 de marzo de 2008, Comisión del Mercado de las Telecomunicaciones (C-82/07, EU:C:2008:143), apartados 25 a 27; sentencias de 6 de octubre de 2010, Base y otros $(\mathrm{C}-389 / 08$, EU:C:2010:584), apartado 30, y de 17 de septiembre de 2015, KPN (C-85/14, EU:C:2015:610), apartado 57. 
las competencias que aquélla asigna a las ANR de manera imparcial, transparente y a su debido tiempo, y también debe disponer de recursos financieros y humanos adecuados para desempeñar estas tareas" ${ }^{\prime \prime 1}$.

Así pues, respecto a la primera cuestión prejudicial planteada por el TS, el Abogado General considera que "en principio, nada se opone a que la normativa de un Estado miembro disponga que una ANR se fusione con otros organismos de regulación y a que esa unión forme una única entidad, como prevé la normativa española. No obstante, el juez nacional debe comprobar que las funciones encomendadas por la Directiva marco a la ANR se ejerzan cumpliendo los requisitos y las garantías establecidos por esta Directiva" ${ }^{\text {. }}$. Es decir, a juicio del Abogado General, la Directiva marco debe interpretarse en el sentido de que no se opone a la fusión de una ANR, en el marco de una reforma institucional, con otras autoridades de regulación, como las de la competencia, el sector postal o el sector de la energía, siempre que las funciones que confía esta Directiva a las ANR puedan ejercerse respetando los requisitos y las garantías establecidos por aquélla, lo que incumbe comprobar al Tribunal nacional ${ }^{83}$.

Ahora pasamos a analizar de forma conjunta las cuestiones prejudiciales segunda y tercera, que se centran en examinar si, tras esta reforma institucional, el cese del Presidente y de un Consejero de la ANR antes de que expire su mandato menoscabaría la garantía de independencia de esta ANR. En concreto, el TS pregunta si la jurispru-

81 Apartados 32 y 33 de las Conclusiones del Abogado General.

82 Apartado 34 de las Conclusiones del Abogado General. Por otro lado, el Abogado General recuerda que el modelo español no es una excepción en la Unión Europea, ya que, el Gran Ducado de Luxemburgo y el Reino de los Países Bajos cuentan también de un organismo único que tiene como misión la regulación de distintos sectores, como los del transporte, el gas, la energía, los servicios postales o incluso las comunicaciones electrónicas. En el Reino Unido, la Oficina de las comunicaciones tiene por misión vigilar el mercado de los sectores de la televisión, la radio y las comunicaciones electrónicas. En Bélgica, en Grecia, en Francia, en Eslovaquia y en Suecia, un único organismo es responsable de la regulación del sector de correos y de las telecomunicaciones. Véase la página web de la Autoridad de regulación de las comunicaciones electrónicas y postales en la siguiente dirección: http://www.arcep.fr/index.php?id=11270\#c21478.

83 Apartado 36 de las Conclusiones del Abogado General. De esta forma, el Abogado General, teniendo en cuenta las consideraciones hechas, propone en sus conclusiones al TJUE que, en cuanto a la primera cuestión prejudicial efectuada, responda al TS de la siguiente manera: "La Directiva 2002/21/ CE del Parlamento Europeo y del Consejo, de 7 de marzo de 2002, relativa a un marco regulador común de las redes y los servicios de comunicaciones electrónicas (Directiva marco), en su versión modificada por la Directiva 2009/140/CE del Parlamento Europeo y del Consejo, de 25 de noviembre de 2009, no se opone a la fusión de una autoridad nacional de reglamentación, en el marco de una reforma institucional, con otras autoridades de regulación, como las de la competencia, el sector postal o el sector de la energía, siempre que las funciones que confía esta Directiva a las autoridades nacionales de reglamentación puedan ejercerse respetando los requisitos y las garantías establecidas en ésta, lo que incumbe comprobar al tribunal nacional." (apartado 56). 
dencia del TJUE recaída con ocasión del caso de Hungría en materia de protección de datos personales puede aplicarse a este caso relativo a comunicaciones electrónicas ${ }^{84}$.

El Abogado General no encuentra razón para aplicar una solución diferente de la adoptada en la sentencia de 8 de abril de 2014, Comisión/Hungría (apartado 42). De este modo, la independencia de las ANRs debe ser efectiva no sólo frente a los actores económicos, sino también frente a los actores políticos. Por otro lado, esto se desprende claramente de los propios textos del Derecho de la Unión ${ }^{85}$.

Por ello, el Abogado General afirma que resulta fundamental que se respete la garantía de independencia y que las ANRs puedan ejercer sus competencias con imparcialidad y sin presiones externas, máxime cuando el Estado miembro ha conservado la propiedad o el control de empresas que garantizan el suministro de redes o de servicios de comunicaciones electrónicas ${ }^{86}$. A este respecto, la composición de las ANRs, la duración del mandato de sus miembros y, sobre todo, la imposibilidad de su cese por causas distintas a las previstas por la ley son otras tantas garantías contra posibles presiones exteriores. Al establecer, en el artículo 3.3 bis, párrafo segundo, de la Directiva marco, que el responsable de la ANR o su suplente, o en su caso, los

84 Véanse los Apartados 50 a 54 de la Sentencia del caso de Hungría.

85 El artículo 3.2 de la Directiva marco indica que los Estados miembros garantizarán la independencia de las ANR, velando por que sean jurídicamente distintas y funcionalmente independientes de todas las entidades suministradoras de redes, equipos o servicios de comunicaciones electrónicas. En cuanto al artículo 3.3 bis, de esta Directiva, añadido por la Directiva 2009/140/CE, se desprende del considerando 13 de esta última que, mediante ese añadido, el legislador de la Unión deseaba precisamente reforzar la independencia de las ANR, "(estableciendo que) debe disponerse expresamente en el Derecho nacional que, en el ejercicio de sus cometidos, la (ANR) responsable de la regulación ex ante del mercado o de la solución de litigios entre empresas esté protegida de intervenciones exteriores o presiones políticas que puedan comprometer su evaluación independiente de los asuntos que se le sometan". Y el legislador de la Unión explica que "tal influencia exterior hace que un órgano legislativo nacional resulte inadecuado para actuar como (ANR) con arreglo al marco regulado". Vista la función reguladora atribuida a las ANR y las competencias que se les conceden a tal fin, la voluntad del legislador de la Unión de reforzar la garantía de independencia de las ANR no es sorprendente. En efecto las ANR, en el marco de las tareas que les asigna la Directiva marco, en particular, han de atribuir derechos individuales y resolver los litigios entre empresas, con la posibilidad de imponer obligaciones. También tienen una cierta potestad reglamentaria, en la medida en que pueden tener que controlar los precios o incluso adoptar medidas correctoras si estiman que el mercado no es competitivo imponiendo obligaciones a las empresas que tiene un poder significativo en ese mercado. Por lo tanto, tienen amplias facultades, como recordó el Tribunal de Justicia en su sentencia de 3 de diciembre de 2009, Comisión/Alemania (C-424/07, EU:C:2009:749).

86 El Tribunal de Justicia ya lo había señalado en su sentencia de 9 de marzo de 2010, Comisión/ Alemania (C-518/07, EU:C:2010:125), en la que había indicado que estas autoridades independientes -en aquel caso de autos, el Tribunal de Justicia se refería no sólo a las autoridades de control competentes para el seguimiento del tratamiento de los datos personales alemanas, sino también a otras autoridades administrativas existentes en el sistema jurídico alemán- ejercen con frecuencia una función reguladora o de otro tipo que exige que deban estar protegidas de la influencia política, sin dejar por ello de estar sujetas a la ley, bajo el control del juez competente. 
miembros del órgano colegial que ejerzan esta función en la ANR o sus suplentes sólo pueden ser cesados por las razones previstas por ley y si, con carácter sobrevenido, no cumplen los requisitos para ejercer sus funciones, "el objetivo del legislador de la Unión es reforzar la garantía de independencia de la ANRs, protegiendo al miembro o miembros con capacidad de decisión frente a cualquier presión externa, en particular la que consiste en amenazar — aun de forma velada — con una finalización de mandato anticipada por motivos distintos a los previstos en la ley. Por lo tanto, el cese anticipado del responsable de una ANR, como en el caso de autos, y, potencialmente, el de uno de los consejeros, por la mera razón de que el Estado miembro ha decidido modificar el modelo institucional de esta ANR puede constituir un menoscabo a la garantía de su independencia" ${ }^{97}$.

Llegados a este punto, nos cuestionamos cómo puede conciliarse en este caso la autonomía institucional de que dispone cada Estado miembro con la garantía de independencia. Para ello, el Abogado General trae a colación la Sentencia del TJUE de 8 de abril de 2014, Comisión/Hungría, y considera que la reestructuración o el cambio de modelo de una autoridad de control o de una ANR no son necesariamente incompatibles con el respeto de la independencia de esta ANR. A la luz de la jurisprudencia mencionada, el Abogado General considera que el Estado miembro de que se trate debe poder establecer disposiciones transitorias que permitan garantizar la independencia de una ANR preparando al mismo tiempo la reestructuración de ésta ${ }^{88}$.

87 Apartados 46 a 48 de las Conclusiones del Abogado General.

88 Apartados 52 a 54 de las Conclusiones del Abogado General. En el caso español, la normativa de 2011 había establecido estas disposiciones, antes de que fueran derogadas por la Ley 3/2013. En efecto, la disposición adicional novena de la Ley 2/2011, relativa a la adaptación de la composición y del número de miembros de los consejos de los organismos reguladores y de la CNMC, preveía medidas transitorias que permitían precisamente preparar la reforma que esta Ley introducía garantizando a la vez la duración del mandato de los presidentes afectados. Así, según dicha Ley, la designación de los nuevos presidentes debía producirse cuando expirara el mandato de quienes ocupaban el puesto de presidente en aquel momento y los nuevos consejeros debían ser designados a partir del momento en que el número de consejeros cuyo mandato no hubiera expirado fuera menor de seis. Del mismo modo, estaba previsto que, a la entrada en vigor de la Ley 2/2011, los vicepresidentes de los consejos de los organismos reguladores continuaran en su cargo hasta la expiración de su mandato, momento en el cual el cargo de vicepresidente de cada organismo quedaría suprimido. No obstante, el mismo Gobierno español señaló que el mantenimiento del mandato de todos los consejeros de la ANR y el resto de organismos de regulación afectados por la reforma podría dar lugar a una nueva entidad costosa e ineficaz. Ahora bien, determinadas disposiciones transitorias que previeran que el mandato del Presidente de la ANR o, en su caso, el de los miembros del órgano colegial que desempeñaran dicha función en su seno llegara a su fin, a juicio del Abogado General, habrían permitido garantizar la independencia de esa ANR. Del mismo modo, aunque la función de un consejero de una ANR se distingue de la de presidente de dicha autoridad, no es menos cierto que, como miembro de ésta, a juicio del Abogado General, debe poder actuar igualmente con total independencia y no debe solicitar ni aceptar instrucción alguna procedente del exterior. Toda vez que la Ley española había previsto para los consejeros el mismo número limitado de causas que podían tener como consecuencia el cese, el cambio de modelo institucional querido por el Gobierno español no puede tener como efecto poner fin pura y simple- 
Por último, a juicio del Abogado General, el artículo 3.3 bis, de la Directiva marco debe interpretarse en el sentido de que el cese del Presidente y de un Consejero de una ANR antes de la finalización de su mandato, como consecuencia de una reforma institucional que tiene por efecto fusionar a esa ANR con otras autoridades de regulación, sin que estén previstas disposiciones transitorias que permitan garantizar el respeto de la duración del mandato del primero y la adaptación del mandato del segundo, menoscaba la independencia de dicha $\mathrm{ANR}^{89}$.

\section{REFLEXIONES FINALES}

Desde un planteamiento general podemos afirmar que la normativa europea sectorial de 2009 aquí señalada profundiza en la decisión de mantener un modelo de regulación económica basado en una organización y en un funcionamiento de Administraciones públicas a nivel nacional que se caracteriza por un gobierno neutral, exento de influencias externas al mercado que pueden proceden de fuerzas políticas o económicas. De este modo se pretende desideologizar aquellas políticas económicas que deban basarse, para su eficacia, en principios técnicos que garanticen el mejor funcionamiento posible de los mercados, sin que dichas políticas económicas puedan ser influidas por divergencias nacionales e ideológicas que, según este modelo, entorpecerían el correcto funcionamiento de los órganos reguladores. Este gobierno así planteado, se basa en el trabajo llevado a cabo por expertos en la materia, y en los conocimientos técnicos del mercado, lo cual no hace desaparecer las discusiones de carácter político o ideológico, pero se sitúan de este modo en un plano diferente, en el que los órganos europeos van adquiriendo un mayor protagonismo.

También es preciso considerar hasta qué punto la autonomía institucional de los Estados Miembros se está viendo cada vez más limitada por el debido respeto al Derecho europeo, y todo lo aquí expuesto es un ejemplo de ello.

En este trabajo tratamos de poner de manifiesto que a pesar del esfuerzo de las Directivas europeas, que regulan aspectos relativos a las ANRs en los sectores diferentes, por el fomento y la consecución de la independencia o neutralidad políti-

mente a su mandato sin establecer disposiciones transitorias. A este respecto, según el Abogado General, la situación inicialmente adoptada por la Ley 2/2011 habría permitido respetar la garantía de independencia de la ANR. Por tanto, a juicio del Abogado General, el TS debe examinar en qué medida se podría haber adaptado el mandato de estos consejeros mediante disposiciones transitorias.

89 El Abogado General en sus conclusiones propone al TJUE que responda al TS de la siguiente forma: "El artículo 3, apartado 3 bis, de la Directiva 2002/21, en su versión modificada, debe interpretarse en el sentido de que el cese del presidente y de un consejero de una autoridad nacional de reglamentación antes de la finalización de su mandato, como consecuencia de una reforma institucional que tiene por efecto fusionar a esa autoridad con otras autoridades de regulación, sin que estén previstas disposiciones transitorias que permitan garantizar el respeto de la duración del mandato del primero y la adaptación del mandato del segundo, menoscaba la independencia de dicha autoridad" (apartado 56). 
ca de los integrantes de las ANRs, la cuestión a día de hoy sigue siendo polémica y compleja, tanto en el ámbito europeo como en el interno de cada Estado miembro. Un ejemplo claro lo hemos visto en la sentencia del TJUE contra Hungría, en la que finalmente el Tribunal declara que Hungría ha incumplido la Directiva 95/46 por haber cesado en el cargo al supervisor de protección de datos antes del periodo de tiempo previsto en su normativa interna, sin que se establezcan medidas transitorias que permitan garantizar que se respeta la duración de su mandato, al considerarlo como una intromisión y falta de independencia.

Una vez que hemos conocido con detenimiento el contenido de la Sentencia del TJUE respecto a Hungría, y tras haber analizado el Auto del TS y las conclusiones del Abogado General en el caso de España debemos plantearnos, al menos, por qué el legislador español, a pesar de la jurisprudencia existente en Europa en el caso de Hungría, aprobó la Ley de creación de la CNMC sin mantener un régimen transitorio para el Presidente y los Consejeros de la antigua CMT y además acometió su destitución. Como hemos comentado a lo largo de este trabajo las conclusiones del Abogado General vaticinaban en el caso español una solución similar a la de Hungría. Ya podemos decir que así ha sido, pues el TJUE y el TS en sus sentencias posteriores han adoptado una solución idéntica que en el citado caso previo. Por tanto, y como era de esperar, se trata de la crónica de una muerte anunciada. 